\title{
Productivity Gaps and Tax Policies Under Asymmetric Trade*
}

\author{
Lucas Bretschger, Center of Economic Research, ETH Zürich. \\ Simone Valente, School of Economics, University of East Anglia.
}

May 11, 2016

Lucas Bretschger, CER-ETH Zurich, Zuerichbergstrasse 18, CH-8032 Zurich, Switzerland. Email: lbretschger@ethz.ch. Phone: +41446322192.

Simone Valente (corresponding author), School of Economics, ARTS 3.50, University of East Anglia, NR4 7TJ Norwich, United Kingdom. Email: s.valente@uea.ac.uk. Phone: +441603591605 .

*Acknowledgment. We owe special thanks to Emiliya Lazarova and Julie Ing for suggestions and feedback as well as to the Associate Editor and Referees for their constructive comments. Any remaining errors are the authors responsibility. Detailed proofs and derivations of the analysis in this article are available on-line as Supplementary Material. Further results and details can be found in the original working paper (Bretschger and Valente, 2016). 
Proposed running head: Productivity Gaps, Taxes and Trade

Send proofs to: Simone Valente (corresponding author), School of Economics, ARTS

3.50, University of East Anglia, NR47TJ Norwich, United Kingdom. Email: s.valente@uea.ac.uk. Phone: +441603591605 . 
Abstract. We build a two-country model of endogenous growth to study the welfare effects of taxes on tradable primary inputs when countries engage in asymmetric trade. We obtain explicit links between persistent gaps in productivity growth and the incentives of resource exporting (importing) countries to subsidize (tax) domestic resource use. The exporters' incentive to subsidize hinges on slower productivity growth and is disconnected from the importers' incentive to tax resource inflows - i.e., rent extraction. Moreover, faster productivity growth exacerbates the importers' incentive to tax, beyond the rentextraction motive. In a strategic tax game, the only equilibrium is of Stackelberg type and features, for a wide range of parameter values, positive exporters' subsidies and positive importers' taxes at the same time.

Keywords: Productivity Gaps, Endogenous Growth, International Trade, Tax Policy.

JEL Classification Numbers: O40, F43 


\section{Introduction}

The recent up-surge in oil prices and the growing relevance of primary commodities in world trade have revived the interest in the international sharing of natural resource rents (WTO, 2011). Fiscal policies are central to the debate since uncoordinated taxation may influence trade outcomes to a great extent, and there are remarkable asymmetries in the fiscal treatment of primary resources. In particular, international comparisons between oil-rich and oil-poor countries reveal that while importers levy oil taxes with varying but often high rates, most oil exporters grant subsidies on domestic oil consumption (Gupta et al. 2002; Metschies, 2005). One crucial question is whether asymmetric trade - i.e., trade of primary resources versus final goods - creates incentives for national governments to impose strategic domestic taxes. A more specific question is why oil-rich countries do subsidize domestic oil use - a stylized fact that, beyond mostly political-economic arguments, is not explained by first principles like social welfare maximization. In this paper, we tackle these issues in a two-country model of endogenous growth which draws an explicit link between persistent gaps in productivity growth and the observed tendency of resource-exporting (importing) countries to subsidize (tax) domestic consumption of primary resources.

The incentives behind resource taxation have traditionally been studied in two parallel strands of literature in international trade and in public economics. Bergstrom (1982) showed that, facing an inelastic world resource supply, importing countries may tax domestic use to extract rents that would otherwise accrue to exporters. The rent-extraction mechanism is reinforced by the introduction of pollution damages (Amundsen and Schöb, 1999) and monopolistic behavior on the supply side (Brander and Djajic, 1983) since the importers' incentive to tax is stronger the higher the rents to be potentially captured and the lower the social benefit from domestic resource consumption (Rubio and Escriche, 2001; Liski and Tahvonen, 2004). The existing literature on this topic neglects however two important aspects.

First, the rent-extraction mechanism does not explain why resource-exporting coun- 
tries subsidize domestic resource use. The observed subsidies may reflect political convenience - e.g. providing benefits to well-organized groups (Tornell and Lane, 1999) and bribing voters (Robinson et al., 2006) - but a clear economic rationale based on first principles and standard behavioral assumptions, like the pursuit of maximal social welfare, is still lacking. Second, most analyses of strategic trade policies hinge on partial equilibrium models that do not consider the role of economic growth and, especially, of international productivity gaps. In this respect, a number of empirical studies present cross-country evidence suggesting that specialization in resource production and exports is negatively correlated to domestic productivity (Lederman and Maloney, 2007). In particular, Bretschger and Valente (2012) show that oil-exporting countries exhibited persistently slower growth in labor productivity but constant income levels relative to oilimporting countries during the last four decades, a plausible reason being the compensating effects of terms of trade. In this paper, we argue that persistent gaps in productivity growth influence the policymakers' incentives to distort trade and may provide new rationales for both the rent-extracting taxes and the defensive subsidies that we observe in the real world.

We tackle the issue in a two-country model of endogenous growth where asymmetric trade is merged with country-specific engines of economic growth: persistent gaps in physical productivity between resource-rich and resource-poor economies originate in different investment rates since $R \& D$ productivity incorporates positive spillovers from past research. Bretschger and Valente (2012) build this theoretical model to show that the world equilibrium is characterized by a balanced growth path that is consistent with the empirical evidence for oil-trading economies: productivity gaps are compensated by terms-of-trade dynamics implying constant relative incomes between the two economic areas. ${ }^{1}$ In the present paper, we extend the analysis of Bretschger and Valente (2012) in three ways, namely studying (i) the welfare effects of domestic resource taxes, (ii) the

\footnotetext{
${ }^{1}$ Persistent productivity gaps are a robust finding of the empirical literature. In endogenous growth models, one possible justification is limited capability of absorbing foreign innovations due to technological requirements (see e.g. Barro and Sala-i-Martin, 2004: Chap.8).
} 
selfish incentives of national governments to deviate from laissez-faire, and (iii) strategic tax games in which exporters' subsidies and importers' taxes can be rationalized as an equilibrium outcome. Our analysis shows that technological differences determine incentives to tax resource flows that are asymmetric for the two countries' governments and are consistent with the observed styilized facts. Specifically, suppose that productivity growth in the resource-importing economy (labeled 'Home') is faster than in the resource-exporting country (labeled 'Foreign'). Then, given an initial laissez-faire equilibrium, Home's government would generate higher domestic welfare by raising positive taxes on imported resources. ${ }^{2}$ Instead, the government of Foreign would increase domestic welfare by subsidizing domestic resource use at a strictly positive rate. Combining these results into a simple strategic tax game, we show that the only equilibrium that may exist with finite rates is a Stackelberg equilibrium in which the resource exporting country moves first. For a wide range of parameter values, the Stackelberg equilibrium implies the coexistence of positive subsidies in Foreign and positive taxes in Home.

With respect to the existing literature, the element of novelty is that our results hinge on productivity differences: the traditional "rent extraction mechanism", which is a pure redistribution effect, does not play any role in Foreign government incentive to subsidize resource use and, at the same time, it is not the exclusive reason behind Home's government incentive to tax resource inflows. Infact, our analysis shows that resource taxes serve different purposes in the two economies because:

(a) In the resource-exporting country, rents are maximized when world resource supply is efficiently allocated between the two countries. Hence, the government of Foreign has an incentive to use the resource tax to set the two countries' relative resource use equal to the efficient level.

(b) In the resource-importing country, the resource tax increases Home's share of world

\footnotetext{
${ }^{2}$ This mechanism hinges on the model prediction whereby Home resource taxes increase Home's relative income share. Bretschger and Valente (2016) provide empirical evidence supporting the positive relationship between importing countries' resource taxes on their income shares.
} 
income by reducing the cost share of resource inputs purchased from Foreign firms - i.e., a variant of the rent-extraction mechanism. Therefore, Home's government has an incentive to use the domestic resource tax to artificially reduce Home's share of world resource use below the efficient level.

In our model, the laissez-faire equilibrium is inefficient because productivity growth rates are determined by spillovers from past $R \& D$. In particular, when $R \& D$ productivity is faster in the Home country, the equilibrium level of Home's share of world resource use is strictly above the efficient level ${ }^{3}$. Combining this result with statements (a) and (b), it follows that laissez-faire provides both governments with incentives to deviate from the market equilibrium. On the one hand, Foreign would like to subsidize domestic resource use in order to raise its own world share up to the efficient level. On the other hand, Home would like to tax domestic use for two reasons: eliminating its own overconsumption of world resources (induced by productivity differences) and pushing its relative resource use further below the efficient level (in order to extract rents). In a nutshell, the rent-extraction mechanism is logically disconnected from Foreign's incentive to subsidize while it is not the unique driver of Home's incentives to tax: both countries' incentives are shaped, instead, by the sign of productivity gaps.

Our results shed further light on the conclusions of the existing literature. With respect to the few previous studies of asymmetric trade with endogenous growth and exhaustible resources (Daubanes and Grimaud, 2010; Peretto and Valente, 2011), the distinctive feature of our analysis is that we assume asymmetric technologies to obtain links between persistent gaps in productivity growth and the observed tendency of resource-exporting (importing) countries to subsidize (tax) domestic resource use. ${ }^{4}$ In

\footnotetext{
${ }^{3}$ This is an intermediate result of our analysis. For given taxes, the ratio between the two countries' demand for resources reflects the ratio between the two countries' final output and the latter ratio is higher the higher is the ratio between the two countries' investment rates determined by the respective R\&D productivities: see equation (25) below.

${ }^{4}$ Daubanes and Grimaud (2010) assume identical productivities via immediate technology diffusion and introduce pollution externalities to analyze a cooperative tax game to correct for environmental damage.
} 
particular, our results go beyond the rent-extraction mechanism by showing that asymmetric spillovers from past research provide (i) an otherwise absent rationale for the rise of subsidies in resource-rich countries and (ii) an additional incentive to tax resource inflows in resource-poor countries.

\section{The Model}

The model comprises two countries, called Home and Foreign and indexed by $i=h, f$, and follows the structure developed in Bretschger and Valente (2012). ${ }^{5}$ Each economy produces a tradable final good, consumed by the residents of both countries, using manmade intermediate inputs and an exhaustible natural resource. Trade is asymmetric since the natural resource stock is exclusively owned by Foreign residents: Home only exports its final good whereas Foreign exports both final goods and resource units. Output growth is driven by $R \& D$ activity that expands the varieties of intermediate inputs (Rivera-Batiz and Romer, 1991). Two market failures affect the domestic equilibrium of each economy: the existence of monopoly rents in intermediates' production, and knowledge spillovers enhancing the productivity of R\&D firms over time.

In this paper, we will treat the symmetric laissez-faire equilibrium as the relevant initial state of affairs and study the welfare consequences of introducing resource taxes set by selfish national governments. Throughout the discussion, however, we also consider efficient equilibria to clarify the role played by market failures in our results. This section thus presents a general specification of the model in which national governments have access to three fiscal instruments that could possibly correct for domestic market failures, i.e., taxes on domestic resource use, subsidies to $R \& D$, and taxes on final producers.

Using conventional notation, the time-derivative and the growth rate of variable $g(t)$ are respectively denoted by $\dot{g}(t) \equiv \mathrm{d} g(t) / \mathrm{d} t$ and $\hat{g}(t) \equiv \dot{g}(t) / g(t)$. Detailed derivations

Peretto and Valente (2011) assume identical R\&D technologies and study the impact of resource booms on innovation rates and relative welfare.

${ }^{5}$ Closed-economy variants of endogenous growth models with natural inputs include Aznar-Marquez and Ruiz-Tamarit (2005), Valente (2011) and Peretto (2012). 
and proofs of the Propositions are collected in the Appendix.

\subsection{Final Producers, Intermediate Sectors and R\&D}

Final Sector. Each country's final sector produces $Y_{i}$ units of a tradable consumption good using $M_{i}$ varieties of differentiated intermediate products, $L_{i}$ units of labor, and $R_{i}$ units of an exhaustible resource, according to

$$
Y_{i}=\int_{0}^{M_{i}}\left(X_{i}\left(m_{i}\right)\right)^{\alpha} d m_{i} \cdot\left(v_{i} L_{i}\right)^{\beta} R_{i}^{\gamma}, \quad i=h, f,
$$

where $X_{i}\left(m_{i}\right)$ is the quantity of the $m_{i}$-th variety of intermediate input, $v_{i}$ is labor productivity, and parameters satisfy $\alpha+\beta+\gamma=1$ with $0<\alpha, \beta, \gamma<1$. The endogenous engine of growth is represented by increases in the mass $M_{i}$ of intermediates' varieties, while labor efficiency grows at the exogenous rate $\hat{v}_{i}=\eta_{i}$. Labor is inelastically supplied: $L_{h}$ and $L_{f}$ are fixed amounts coinciding with the respective population sizes. The law of one price holds for all traded goods: the quantities $\left(Y_{h}, Y_{f}\right)$ are sold at the respective world prices $\left(P_{Y}^{h}, P_{Y}^{f}\right)$ and the exhaustible resource is sold to all final producers at the same world price $P_{R}$. The wage rate and the price of each intermediate, respectively denoted by $P_{L}^{i}$ and $P_{X\left(m_{i}\right)}^{i}$, are country-specific. Production costs in the final sector are affected by proportional taxes on the purchases of intermediate inputs and on resource use, respectively denoted by $b_{i}$ and $\tau_{i}$. The resulting profit-maximizing conditions read ${ }^{6}$

$$
\begin{aligned}
P_{R} R_{i}\left(1+\tau_{i}\right) & =\gamma P_{Y}^{i} Y_{i}, \\
P_{X\left(m_{i}\right)}^{i}\left(1+b_{i}\right) & =\alpha P_{Y}^{i}\left(X_{i}\left(m_{i}\right)\right)^{\alpha-1}\left(v_{i} L_{i}\right)^{\beta} R_{i}^{\gamma},
\end{aligned}
$$

where $(3)$ is valid for each variety $m_{i} \in\left[0, M_{i}\right]$.

Intermediate Sector. Each variety of intermediate is produced by a monopolist who holds the relevant patent and maximizes profits $\Pi_{i}\left(m_{i}\right)$ taking the demand schedule (3) as given. Producing one unit of intermediate requires $\varsigma$ units of final good, where

\footnotetext{
${ }^{6}$ Both $b_{i}$ and $\tau_{i}$ are constant over time. The assumption is innocuous since decentralizing efficient allocations requires implementing constant tax rates, as shown in section 3.
} 
$\varsigma>0$ represents a constant marginal cost that equally applies to each variety. Profit maximization implies the mark-up rule

$$
P_{X\left(m_{i}\right)}^{i}=(\varsigma / \alpha) P_{Y}^{i} \text { for each } m_{i} \in\left[0, M_{i}\right]
$$

and therefore symmetric quantities and profits across monopolists.

RED Sector. The mass of intermediates' varieties $M_{i}$ grows over time by virtue of R\&D activity pursued by competitive firms that develop new blueprints and sell the relevant patents to new monopolists. We represent $\mathrm{R} \& \mathrm{D}$ firms as a consolidated sector earning zero profits due to free-entry. Developing blueprints requires investing units of the domestic final good, with marginal productivity $\phi_{i}$. R\&D investment is subsidized by the domestic government at rate $a_{i}>0$. Denoting by $Z_{i}$ the total amount invested by R\&D firms, aggregate $\mathrm{R} \& \mathrm{D}$ investment in country $i$ is $Z_{i}\left(1+a_{i}\right)$, and the increase in the mass of varieties equals

$$
\dot{M}_{i}(t)=\phi_{i}(t) \cdot\left(1+a_{i}\right) \cdot Z_{i}(t) .
$$

The productivity of the R\&D sector is affected by knowledge spillovers whereby the current productivity of investment, $\phi_{i}$, increases with the state of the art, conveniently measured by the ratio $M_{i} / Y_{i}$. The spillover function is

$$
\phi_{i}(t) \equiv \varphi_{i} \cdot\left(M_{i}(t) / Y_{i}(t)\right)
$$

where $\varphi_{i}>0$ is a constant parameter. From from (5) and (6), the growth rate of intermediates' varieties is proportional to the economy-wide rate of $R \& D$ investment,

$$
\hat{M}_{i}(t)=\varphi_{i}\left(1+a_{i}\right) \cdot\left(Z_{i}(t) / Y_{i}(t)\right)
$$

a relationship that is empirically plausible (Barro and Sala-i-Martin, 2004: p.300-302) and implies the elimination of scale effects.

\subsection{Resource Extraction in Foreign}

The owners of extracting firms are households in Foreign, each of whom earns the same fraction $1 / L_{f}$ of rents. Extracting firms are competitive and costlessly extract the resource 
flow $R(t)$ from a non-renewable stock of resource $Q(t)$, taking the world resource price $P_{R}$ as given. Extraction equals the sum of the resource units employed in the two countries, $R(t)=R_{h}(t)+R_{f}(t)$, and firms maximize present-value profits

$$
\int_{0}^{\infty} P_{R}(t) R(t) e^{-\int_{t}^{\infty} r_{f}(v) d v} d t
$$

subject to the dynamic resource constraint $\dot{Q}(t)=-R(t)$. The solution to this dynamic problem is characterized by the conditions

$$
\begin{aligned}
\hat{P}_{R}(t) & =r_{f}(t), \\
Q_{0} & =\int_{0}^{\infty} R(t) d t .
\end{aligned}
$$

Equation (9) is Hotelling's rule: the resource price must grow at a rate equal to the rate of return to investment. Equation (10) is the intertemporal resource constraint requiring asymptotic exhaustion of the resource stock.

\subsection{Governments, Households and Trade Balance}

Governments. In country $i=h, f$, public $\mathrm{R} \& \mathrm{D}$ subsidies are financed by taxes on intermediates' purchases and on resource use. The public budget is balanced via per capita lump-sum transfers $F_{i}$ :

$$
a_{i} P_{Y}^{i} Z_{i}=F_{i} L_{i}+b_{i} M_{i} P_{X}^{i} X_{i}+\tau_{i} P_{R} R_{i}
$$

Households. Economy $i$ is populated by $L_{i}$ homogeneous households that solve a two-step consumer problem. First, agents decide how to allocate expenditures between imported and domestically-produced final goods. Denoting by $c_{i}^{j}$ the quantity of the good produced in country $j$ and individually consumed in country $i$, the instantaneous utility of each resident in country $i$ reads

$$
u_{i}\left(c_{i}^{h}, c_{i}^{f}\right)=\ln \left[\left(c_{i}^{h}\right)^{\epsilon}\left(c_{i}^{f}\right)^{1-\epsilon}\right], \quad 0<\epsilon<1,
$$

where the weighting parameters, $\epsilon$ and $1-\epsilon$, indicate the preference taste for Home and Foreign goods, respectively. Maximizing (12) subject to the expenditure constraint

$$
E_{i}^{c} / L_{i}=P_{Y}^{h} c_{i}^{h}+P_{Y}^{f} c_{i}^{f}
$$


where $E_{i}^{c}$ is aggregate consumption expenditure in country $i$, we obtain the indirect utility function $\bar{u}_{i}=\ln \left[\omega \cdot\left(E_{i}^{c} / L_{i}\right)\right]$, where $\omega \equiv \omega\left(P_{Y}^{h}, P_{Y}^{f}\right)$ is a weighted average of final goods' prices (see Appendix). In the second step, agents choose the time profile of expenditures by maximizing present-value utility

$$
U_{i} \equiv \int_{0}^{\infty} e^{-\rho t} \cdot \ln \left[\left(\omega(t) \cdot\left(E_{i}^{c}(t) / L_{i}\right)\right] d t,\right.
$$

where $\rho>0$ is the pure time-preference rate, and the path of $\omega(t)$ is taken as given by the household. Maximizing (14) subject to the household wealth constraint (see Appendix) yields the Keynes-Ramsey rule

$$
\hat{E}_{i}^{c}(t)=r_{i}(t)-\rho
$$

Trade. Assuming balanced trade, the value of Foreign total exports - resources plus exported consumption goods - must equal the value of final goods imported from Home,

$$
P_{R} R_{h}+P_{Y}^{f} L_{h} c_{h}^{f}=P_{Y}^{h} L_{f} c_{f}^{h}
$$

The resource-rich economy exhibits a structural deficit in final-goods trade, and this asymmetric structure is the source of the rent-extraction mechanisms typically encountered in the related literature. Considering the aggregate constraints, we simplify the notation by denoting aggregate $\mathrm{R} \& \mathrm{D}$ expenditures of country $i$ as $E_{i}^{d} \equiv P_{Y}^{i} Z_{i}\left(1+a_{i}\right)$ and aggregate expenditures in intermediates' production as $E_{i}^{x} \equiv P_{Y}^{i} \varsigma M_{i} X_{i}$. Consequently, the two economies satisfy

$$
\begin{aligned}
& E_{h} \equiv E_{h}^{c}+E_{h}^{d}+E_{h}^{x}=P_{Y}^{h} Y_{h}-P_{R} R_{h}, \\
& E_{f} \equiv E_{f}^{c}+E_{f}^{d}+E_{f}^{x}=P_{Y}^{f} Y_{f}+P_{R} R_{h},
\end{aligned}
$$

where $E_{i} \equiv E_{i}^{c}+E_{i}^{d}+E_{i}^{x}$ may be interpreted as an index of gross aggregate expenditures in country $i .^{7}$ Equation (17), in particular, shows that total expenditures in Home equal

\footnotetext{
${ }^{7}$ If we subtract intermediate expenditures to the gross expenditure index, we obtain the national accounting definition of gross domestic income $G D I_{i}=E_{i}-E_{i}^{x}$. In the present discussion of the theoretical model, we only consider the comprehensive measure of expenditure $E_{i}$ because it considerably simplifies the calculations as well as the exposition. The accounting definition the national accounting definition of gross domestic income $G D I_{i}$ obviously yields identical results (see Bretschger and Valente, 2012).
} 
the value of final output less the value of resource rents paid to Foreign resource owners.

\subsection{World Equilibrium}

The world equilibrium exhibits three fundamental properties: (i) interest rate parity, (ii) balanced growth with stable expenditure shares, and (iii) a constant equilibrium level of relative resource use. In the present context, result (iii) deserves special emphasis because the analysis of strategic taxation is entirely based on the relationship between national welfare and relative resource use.

Interest rate parity. In each country $i$, the rate of return to investment in terms of domestic final output is given by the growth rate of physical productivity in the domestic final sector, denoted by $\Omega_{i}$ and equal to a weighted sum of the growth rates of the mass of varieties, of labor efficiency and of resource use (see Appendix):

$$
r_{i}-\hat{P}_{Y}^{i}=\Omega_{i} \equiv \frac{\alpha(1-\alpha)\left(1+a_{i}\right)}{1+b_{i}} \varphi_{i}+\frac{\beta}{1-\alpha} \eta_{i}+\frac{\gamma}{1-\alpha} \hat{R}_{i}
$$

The country-specific terms in the right hand side of (19) imply that Home and Foreign may exhibit persistent gaps in productivity growth as a result of differences in structural parameters $\left(\varphi_{i}, \eta_{i}\right)$ or in policy variables $\left(a_{i}, b_{i}\right)$. Equilibrium in trade and symmetric preferences imply that physical productivity differentials are compensated by terms-oftrade dynamics (see Appendix):

$$
\hat{P}_{Y}^{h}-\hat{P}_{Y}^{f}=\Omega_{f}-\Omega_{h} .
$$

Result (20) is linked to our assumption of a unit elasticity of substitution between traded goods $^{8}$ and implies that the world equilibrium is characterized by interest rate parity: results (19) and (20) yield $r_{h}=r_{f}$.

Balanced growth. Interest rate parity implies that consumption expenditures grow at the same rate in the two countries: by the Keynes-Ramsey rule (15), we have $\hat{E}_{h}=\hat{E}_{f}=$

\footnotetext{
${ }^{8}$ Relative income shares with endogenous growth are discussed in Grossman and Helpman (1990), Feenstra (1996) and Valente (2009).
} 
$r_{i}-\rho$ with $r_{h}=r_{f}$. Therefore, the growth rates of physical final output, resource use, and mass of varieties, equal (see Appendix)

$$
\begin{aligned}
& \hat{Y}_{h}=\Omega_{h}-\rho \text { and } \hat{Y}_{f}=\Omega_{f}-\rho, \\
& \hat{R}_{h}=\hat{R}_{f}=-\rho, \\
& \hat{M}_{i}=\varphi_{i} \alpha(1-\alpha)\left(1+a_{i}\right)\left(1+b_{i}\right)^{-1}-\rho,
\end{aligned}
$$

at each point in time. We stress two relevant implications of this balanced-growth equilibrium. First, since $\left(P_{Y}^{h} Y_{h}\right) /\left(P_{Y}^{f} Y_{f}\right)$ is constant, the two countries exhibit constant shares in the world market for final goods and thereby stable shares of world income. Second, constant growth rates at each point in time allow us to obtain closed form solutions for both consumption paths and for present-value welfare levels.

Relative final output and relative resource use. Our analysis of taxation will hinge on two equilibrium relationships that link the two countries' propensities to invest and their respective shares in final output and in world resource use. First, we define a convenient index of gross investment rate $I_{i}$ as the sum of the shares of domestic output invested in $\mathrm{R} \& \mathrm{D}$ and used in intermediates' production. In equilibrium, such investment rate equals (see Appendix)

$$
I_{i} \equiv \frac{E_{i}^{d}}{P_{Y}^{i} Y_{i}}+\frac{E_{i}^{x}}{P_{Y}^{i} Y_{i}}=\underbrace{\frac{\varphi_{i} \alpha(1-\alpha)\left(1+a_{i}\right)-\rho\left(1+b_{i}\right)}{\varphi_{i}\left(1+b_{i}\right)}}_{\text {R\&D investment rate }}+\underbrace{\frac{\alpha^{2}}{1+b_{i}}}_{\text {Intermediates }}
$$

for each country $i=h, f$. Considering market shares in final output, we combine the expenditure constraints (17)-(18) with (24) to obtain (see Appendix)

$$
\frac{P_{Y}^{h} Y_{h}}{P_{Y}^{f} Y_{f}}=\frac{\epsilon}{1-\epsilon} \cdot \frac{1-I_{f}}{1-I_{h}} .
$$

Expression (25) shows that the value of Home's final output (relative to Foreign) increases with the taste parameter of world consumers for Home's final goods (relative to Foreign) and is positively related to Home's investment rate (relative to Foreign). Now consider Home's relative resource use, defined as $\theta(t) \equiv R_{h}(t) / R_{f}(t)$. Result (22) implies that, in equilibrium, relative resource use is constant over time. Importantly, this equilibrium 
level $\theta(t)=\bar{\theta}$ is directly affected by both countries' investment rates through (25) because the countries' relative demands for resources depend on the two countries' relative output levels: combining (25) with the final sectors' resource demand schedules (2), we obtain

$$
\bar{\theta}=\frac{1+\tau_{f}}{1+\tau_{h}} \cdot \frac{\epsilon}{1-\epsilon} \cdot \frac{1-I_{f}}{1-I_{h}} .
$$

The world resource allocation is thus determined by three components: the relative distortion induced by domestic taxes, the relative consumers' taste for the countries' final goods, and the relative investment rates. This result is crucial for understanding the governments' incentives to enact strategic resource taxes. Infact, we will show that each government is tempted to use the domestic resource tax so as to induce a specific level of $\bar{\theta}$ that is associated to maximal domestic welfare.

\section{Laissez-Faire and Efficient Allocations}

This section describes the characteristics of two benchmark allocations: the symmetric laissez-faire equilibrium, in which all taxes and subsidies are set to zero, and the efficient resource allocation arising when total resource supply is efficiently split between the two countries. In order to define the latter, we exploit the concept of symmetric conditionally efficient equilibrium, i.e., the equilibrium arising when both governments neutralize domestic market failures through appropriate fiscal instruments.

We stress that, from the logical point of view, the 'initial state of affairs' that is relevant to our analysis is the laissez-faire equilibrium: our aim is to understand what would be the welfare effect of imposing a resource tax or a resource subsidy in each country starting from an initial situation without public intervention. In contrast, we treat the concept of efficient allocation as an expositional device. The first reason behind this strategy is practical. Since the laissez-faire equilibrium is inherently inefficient, it is difficult to judge prima facie whether a government's incentive to deviate from laissezfaire reflects the existence of pure gains from international redistribution or the existence of unexploited gains induced by market failures. In this respect, the efficient allocation 
can be treated as an alternative benchmark state of affairs which allows us to determine the existence of pure gains from redistribution in isolation from the other mechanisms operating under laissez-faire. ${ }^{9}$

The second reason why the efficient allocation is not our preferred 'initial state of affairs' is logical. In section 3.2, we show that the efficient resource allocation can be viewed as an equilibrium that would be achieved if each government were to maximize domestic welfare at given international prices. In our welfare analysis of resource taxes (section 4 ), we postulate that the incentive for a government to deviate from an initial state of affairs is the government's expectation to earn domestic welfare gains, and the calculation of these gains includes terms-of-trade effects. Our hypothesis that governments are able to infer the impact of national taxes on international prices thus appears at odds with the view that the initial state of affairs is a symmetric efficient equilibrium. ${ }^{10}$ For this reason, we consider the laissez-faire equilibrium as the relevant initial state of affairs in our welfare analysis.

\subsection{Laissez-Faire Resource Allocation}

Suppose that taxes and subsidies are set to zero in each country: $\tau_{i}=b_{i}=a_{i}=0$. The laissez-faire equilibrium is inefficient by construction since monopolistic competition and knowledge spillovers imply a misallocation of domestic output between consumption and investment within each country. The crucial aspect, however, concerns the implications for 'aggregate efficiency in resource use', that is, how laissez-faire changes the way in

\footnotetext{
${ }^{9}$ This point will become clearer in section 4 , which shows that, starting from an efficient resource allocation, the Home government can raise national welfare to the detriment of Foreign residents by raising a positive tax on domestic resource. This is the traditional rent extraction incentive which results from the asymmetric structure of international trade: it operates even under efficiency conditions and is therefore a pure redistribution effect.

${ }^{10}$ Alternatively, if we interpret efficient allocations as the equilibrium outcome of a cooperative game in which world welfare is maximized, the hypothesis that the initial state of affairs is an efficient equilibrium appears inconsistent with our hypothesis that governments are selfish (i.e., they only care about national welfare maximization).
} 
which the world resource supply is distributed between the two countries. From (24) and (26), relative resource use under laissez-faire equals

$$
\theta_{\mathcal{L F}} \equiv \frac{\epsilon}{1-\epsilon} \cdot \frac{1-\alpha+\left(\rho / \varphi_{f}\right)}{1-\alpha+\left(\rho / \varphi_{h}\right)}
$$

Equation (27) shows that, under laissez-faire, the world resource allocation is affected by cross-country differences in $R \& D$ productivity because spillovers from past research distort Home and Foreign investment rates and thereby the two countries' relative resource demand. The important information contained in expression (27) is that the extent by which the world's allocation of resources is inefficient is determined by the size of the gap between the two countries' parameters of R\&D productivity, $\varphi_{h}$ and $\varphi_{f}$. Faster productivity growth in a given country pushes up the country's share of resource use because - as shown in (25) above - faster productivity growth drives up the country's share in world final output.

\subsection{Efficient Resource Allocation}

In this subsection, we determine the efficient allocation of total resource supply between the two countries. To this aim, we exploit the concept of conditionally efficient symmetric equilibrium, i.e., the equilibrium that would arise if both national governments were to neutralize the respective domestic market failures through appropriate fiscal instruments. Suppose that government $i$ eliminates the domestic inefficiencies generated by monopoly pricing and $R \& D$ spillovers. The resulting allocation in country $i$ is called "conditionally efficient" according to the following

Definition 1 (Domestic conditional efficiency) An allocation is conditionally efficient for country $i$ if domestic output is allocated so as to maximize present-value utility $U_{i}$ subject to the technology, income, and resource constraints faced by country $i$ at given international prices.

The conditionally efficient allocation ( $C E$-allocation, hereafter) is similar to the welfaremaximizing allocation that characterizes social optimality in closed-economy models. 
However, in the present context, conditional efficiency and optimality are quite different concepts. In closed economies, the welfare-maximizing allocation is chosen by a social planner endowed with full control over all the elements of the allocation. The $C E$ allocation in country $i$, instead, postulates maximal domestic utility within country $i$ at given international prices. Since international prices are influenced by the fiscal policies of both countries, there is no general presumption that governments actually wish to implement the $C E$-allocations in practice. If governments can infer all the general-equilibrium effects generated by fiscal policy, international prices are not taken as given and a selfish government may find it desirable to deviate from domestic conditional efficiency as long as such deviation increases domestic welfare to the detriment of the other country's welfare (this is indeed the case for the Home country, as shown in the next section). In line with this reasoning, we do not interpret the $C E$-allocation as a national target. Instead, we use the symmetric $C E$-equilibrium as an analytical device allowing us to determine the efficient resource allocation at the world level, i.e., how would the total resource supply be split between the two countries if all inefficiencies were internalized.

We characterize $C E$-allocations by denoting the relevant variables by tildas. In Home, the $C E$-allocation is represented by the paths of imported resource flows and expenditures (in consumption, intermediates' production and R\&D activity), that maximize Home's indirect utility subject to the final-good technology, the intermediate-good technology, the R\&D technology, and Home's expenditure constraint:

$$
\left\{\tilde{R}_{h}, \tilde{E}_{h}^{c}, \tilde{E}_{h}^{x}, \tilde{E}_{h}^{d}\right\}_{t=0}^{\infty}=\arg \max U_{h} \text { s.t. }(1),(7),(17)
$$

where $U_{h}$ in (14) is maximized taking international prices as given, and the R\&D externality is fully taken into account through constraint (7). In Foreign, the $C E$-allocation is represented by the paths of domestic resource use, exported resources, and expenditures that maximize Foreign utility subject to the technology constraints, the aggregate expenditure constraint, and the exhaustible resource constraint:

$$
\left\{\tilde{R}_{h}, \tilde{R}_{f}, \tilde{E}_{f}^{c}, \tilde{E}_{f}^{x}, \tilde{E}_{f}^{d}\right\}_{t=0}^{\infty}=\arg \max U_{f} \text { s.t. (1), (7), (17) and } \dot{Q}=-R_{h}-R_{f} \text {. }
$$


Solving these maximization problems yields the following result (proof in Appendix). If both economies display conditional efficiency, the resulting level of relative resource use is

$$
\tilde{\theta}=\frac{\epsilon}{1-\epsilon} .
$$

Expression (28) shows that the efficient relative resource use is exclusively determined by preference parameters, with no role played by technology. The intuition is that, in a symmetric $C E$-equilibrium, technological spillovers are internalized by means of efficient R\&D subsidies and do not distort the countries' relative demand for resources. ${ }^{11}$ Indeed, the notion of efficiency embodied in (28) applies to resource allocation at the world level: the relative demands for resources from the two countries' final sectors only reflect the relative tastes of world consumers for the two countries' final goods.

Armed with these results, we can determine a more general concept, the efficient level of relative resource use, as follows:

Definition 2 (Efficient resource allocation) At the world level, total resource supply is efficiently allocated between the two countries when

$$
\theta=\theta_{E} \equiv \frac{\epsilon}{1-\epsilon}
$$

The notion of efficient resource allocation (29) is more general than that contained in (28) because relative resource use may be efficient at the world level independently of whether the two countries have internalized their respective market failures, i.e., regardless of whether the world general equilibrium is Pareto efficient in every respect. For example, relative resource use may be efficient even in the laissez-faire equilibrium: if there are no productivity gaps, we have $\varphi_{h}=\varphi_{f}$ and equation $(27)$ implies that $\theta_{\mathcal{L F}}$ coincides with the efficient level $\theta_{E}$.

\footnotetext{
${ }^{11}$ The optimal R\&D subsidies and taxes that allow national governments to decentralize the $C E$ allocation are constant over time because the optimal propensities obtained from the respective domestic social problems preserve balanced growth at the world level (see Appendix).
} 


\subsection{Preliminary Comparison}

Comparing the efficient relative resource use $\theta_{E}$ with the laissez-faire level $\theta_{\mathcal{L F}}$, expressions (27) and (29) immediately show that under laissez-faire, a country's relative resource use is inefficiently high (from the point of view of the world's resource allocation) when its RED productivity is higher than in the other country:

$$
\varphi_{h} \gtrless \varphi_{f} \quad \text { implies } \quad \theta_{\mathcal{L F}} \gtrless \theta_{E} \text {. }
$$

The reason behind result (30) follows directly from (27): under laissez faire, technological R\&D spillovers are not internalized and the country exhibiting stronger R\&D spillovers displays faster productivity growth, a higher share in world final output and thereby a higher relative resource use. More importantly, result (30) implies different incentives for national governments to deviate from either regime, as we show below.

\section{Taxation and Welfare}

This section provides a comprehensive study of the welfare effects of resource taxes. As a first step, we show analytically that national welfare is a hump-shaped function of the domestic resource tax in each country. These welfare curves imply that government $i$ might use the domestic tax $\tau_{i}$ to move the world equilibrium towards the allocation that maximizes domestic welfare. This reasoning hinges on the idea that the existence of potential welfare gains for a given country represents an incentive for that country's government to deviate unilaterally from the initial state of affairs. Clearly, for this logic to be coherent, we need to assume that national governments recognize the existence of potential domestic welfare gains, which in turn requires that governments do not take international prices as given: since the 'welfare curves' incorporate all the general equilibrium effects of resource taxes, a government aiming at the curve's peak is implicitly calculating the terms-of-trade effects induced by changes in the resource tax.

Building on this notion of 'national incentives', we show that the two countries wish to deviate from laissez-faire for quite different reasons. The resource-exporting country seeks 
an efficient world resource allocation, i.e., Foreign government has an incentive to use resource taxes in order to recollect the unexploited gains generated by R\&D spillovers. The resource-importing country, instead, seeks an inefficient resource allocation, i.e., Home's government has a double incentive to use resource taxes: recollecting unexploited gains (induced by R\&D spillovers) as well as earning pure gains from redistribution (determined by the rent-extraction mechanism). These conclusions, and the specific scenario arising when the Home economy displays stronger R\&D spillovers than the Foreign economy, are formally derived below.

\subsection{The Rent-Extraction Mechanism}

A basic property of the present model is that Home's resource tax affects the world income distribution whereas the Foreign resource tax does not change income shares. In every equilibrium, Home's share of world total expenditures equals

$$
\frac{E_{h}}{E_{h}+E_{f}}=\underbrace{\frac{\left(P_{Y}^{h} Y_{h}\right) /\left(P_{Y}^{f} Y_{f}\right)}{1+\left(P_{Y}^{h} Y_{h}\right) /\left(P_{Y}^{f} Y_{f}\right)}}_{\text {Final output share }} \cdot \underbrace{\left(1-\tilde{\gamma}_{h}\right)}_{\text {Net of rents to Foreign }}
$$

where $\tilde{\gamma}_{h} \equiv \gamma\left(1+\tau_{h}\right)^{-1}$ is the tax-adjusted resource elasticity in final production in Home. Expression (31) shows that Home's expenditure share is the product of two factors. The first is Home's share in world final output, which is independent of resource taxes by result (25). ${ }^{12}$ The second factor represents the effect of Home's resource dependence: from (2), domestic producers must use a fraction $\tilde{\gamma}_{h}$ of revenues from final-good sales to purchase imported resources. By definition, $\tilde{\gamma}_{h} \equiv \gamma\left(1+\tau_{h}\right)^{-1}$ is affected by the Home resource tax whereas it is independent of Foreign resource tax. Therefore, an increase in $\tau_{h}$ increases Home's share of world expenditures through a decline in $\tilde{\gamma}_{h}$ whereas variations in $\tau_{f}$ leave expenditure shares unaffected. This result hinges on the asymmetric structure of

\footnotetext{
${ }^{12}$ The intuition is that variations in $\tau_{h}$ or $\tau_{f}$ induce offsetting variations in physical output quantities and in physical output prices such that the ratio between the values of the two countries' output is unchanged (Bretschger and Valente, 2012). These opposite price-quantity movements appear explicitly in expressions (36)-(37) below.
} 
trade and is a variant of Bergstrom's (1982) rent-extraction mechanism whereby resource taxes in the importing country capture part of the rents that would otherwise accrue to foreign residents. It follows that Home's government may be tempted to increase its share of world income by artifically reducing its resource demand via a higher domestic resource tax. We show below that this is a concrete temptation: Home's domestic welfare is indeed higher when Home's relative resource use is inefficiently low.

\subsection{Welfare Curves}

Importantly, the balanced-growth property of the world equilibrium implies that consumption paths and utility levels can be solved in closed form (see Appendix for detailed derivations). In the two countries, present-value welfare equals

$$
\begin{aligned}
& U_{h}=\varkappa_{h}+\frac{1}{\rho} \ln \left[p_{0}^{1-\epsilon} \cdot Y_{h}(0) \cdot \bar{\sigma}_{h}^{c}\right], \\
& U_{f}=\varkappa_{f}+\frac{1}{\rho} \ln \left[p_{0}^{-\epsilon} \cdot Y_{f}(0) \cdot \bar{\sigma}_{f}^{c}\right],
\end{aligned}
$$

where $\varkappa_{i}$ is a constant factor independent of resource taxes, $p_{0} \equiv P_{Y}^{h}(0) / P_{Y}^{f}(0)$ is the initial relative price of the Home final good, and $\bar{\sigma}_{i}^{c} \equiv E_{i}^{c} /\left(P_{Y}^{h} Y_{i}\right)$ is the equilibrium share of consumption over domestic output in country $i$. Specifically, the consumption propensities equal

$$
\begin{aligned}
& \bar{\sigma}_{h}^{c}=1-I_{h}-\frac{\gamma}{1+\tau_{h}}, \\
& \bar{\sigma}_{f}^{c}=1-I_{f}+\frac{\gamma}{1+\tau_{h}} \cdot \frac{\epsilon}{1-\epsilon} \cdot \frac{1-I_{f}}{1-I_{h}},
\end{aligned}
$$

respectively. These results allow us to calculate the marginal effect of an increase in the domestic resource tax on domestic welfare, $\mathrm{d} U_{i} / \mathrm{d} \tau_{i}$, for each country. In general, the terms in square brackets in (32)-(33) imply that variations in $\tau_{i}$ entail three effects: (i) on terms of trade, (ii) on domestic physical output, and (iii) on consumption propensity. ${ }^{13}$ The direction of the first two effects is intuitive: an increase in the Home (Foreign) resource tax increases the relative price of the Home (Foreign) good and reduces Home

\footnotetext{
${ }^{13}$ See the Appendix for detailed proofs of the statements reported in this section.
} 
(Foreign) physical output. Instead, the direction of the consumption-propensity effect i.e. the $\operatorname{sign}$ of $\mathrm{d} \ln \bar{\sigma}_{i}^{c} / \mathrm{d} \tau_{i}$ - is asymmetric as it is evident from (34)-(35). In Home, the resource tax increases the ratio between consumption and final output:

$$
\rho \cdot \frac{\mathrm{d} U_{h}}{\mathrm{~d} \tau_{h}}=\underbrace{(1-\epsilon) \frac{\mathrm{d} \ln p_{0}}{\mathrm{~d} \tau_{h}}}_{\text {Terms of Trade (+) }}+\underbrace{\frac{\mathrm{d} \ln Y_{h}(0)}{\mathrm{d} \tau_{h}}}_{\text {Physical Output (-) }}+\underbrace{\frac{\mathrm{d} \ln \bar{\sigma}_{h}^{c}}{\mathrm{~d} \tau_{h}}}_{\text {Consumption Share (+) }} .
$$

In Foreign, instead, an increase in the domestic resource tax leaves the consumptionoutput ratio unchanged: since $\mathrm{d} \ln \bar{\sigma}_{f}^{c} / \mathrm{d} \tau_{f}=0$, the marginal welfare effect of the Foreign tax only depends on the relative strength of the variations in terms of trade and physical output,

$$
\rho \cdot \frac{\mathrm{d} U_{f}}{\mathrm{~d} \tau_{f}}=\epsilon \frac{\mathrm{d} \ln p_{0}^{-1}}{\mathrm{~d} \tau_{f}}+\frac{\mathrm{d} \ln Y_{f}(0)}{\mathrm{d} \tau_{f}} .
$$

The asymmetric effects of Home and Foreign taxes on the respective consumption propensities are directly linked to the rent-extraction mechanism described in the previous subsection: in Home, the resource tax increases domestic disposable income and thereby the value of consumption expenditures relative to domestic final output. In Foreign, instead, variations in $\tau_{f}$ do not affect the world income distribution and thereby Foreign' propensity to consume.

The contrasting effects of resource taxes on output prices and physical quantities imply that, in each country, the welfare-tax relationship $U_{i}\left(\tau_{i}\right)$ is hump-shaped: there exists a unique level of the domestic resource tax, $\tau_{i}^{\max }$, that maximizes domestic welfare $U_{i}\left(\tau_{i}\right)$ for a given state of affairs in the other country. Importantly, the model structure implies that, for each country $i$, the welfare-maximizing domestic tax rate $\tau_{i}^{\max }$ is always associated to a specific level of relative resource use, which we denote by $\theta_{i}^{\max }$. The following Proposition establishes that the welfare-maximizing taxes of the two countries are necessarily associated with different equilibria: the two governments cannot simultaneously implement the respective $\tau_{i}^{\max }$ because Home would prefer a lower level of relative resource use. 
Proposition 3 In Foreign, implementing the welfare-maximizing resource tax $\tau_{f}^{\max }$ always implies an efficient resource allocation

$$
\bar{\theta}=\theta_{f}^{\max }=\frac{\epsilon}{1-\epsilon} .
$$

In Home, implementing the welfare-maximizing resource tax $\tau_{h}^{\max }$ always implies inefficiently low relative resource use

$$
\bar{\theta}=\theta_{h}^{\max }<\frac{\epsilon}{1-\epsilon} .
$$

Proposition 3 shows that resource taxes serve different purposes in the two countries. Result (38) establishes that Foreign welfare is maximal when relative resource use coincides with the efficient level. The reason is that Foreign firms act as price takers and thus earn maximal rents when total supply is split between the two countries in 'efficient proportions' from an aggregate perspective. The consequence is that the Foreign goverment may use $\tau_{f}$ to induce an efficient level of relative resource use. Home's government, instead, always has an incentive to deviate from efficiency in the world's resource allocation: from (39), domestic welfare is higher if Home pushes its relative resource use below the efficient level because a lower demand for primary imports raises Home's income share via the rent extraction mechanism. Consequently, Home may use $\tau_{h}$ to distort the allocation in order to raise its disposable income and welfare to the detriment of Foreign residents. More generally, Proposition 3 implies that if both national governments fully recognize all the general-equilibrium effects of the respective resource taxes, the independent pursuit of maximal domestic welfare would determine conflicting objectives: each government would seek a different equilibrium level of relative resource use. This is a very general conclusion because neither (38) nor (39) assume that the two economies are starting from a specific equilibrium.

\subsection{Selfish Incentives to Deviate}

Proposition 3 may in principle be applied to any initial state of affairs. As noted before, our reference benchmark is the symmetric laissez-faire equilibrium. However, it is in- 
structive to begin our discussion with a hypothetical initial state of affairs characterized by efficiency in resource allocation: this exposition will simplify the interpretation of the results holding under laissez-faire.

Proposition 4 Given an equilibrium characterized by the efficient level of relative resource use, $\theta=\theta_{E}$, we have $d U_{h} / d \tau_{h}>0$ and $d U_{f} / d \tau_{f}=0$.

Since a resource tax in a given country reduces that country's share of world resource use, Proposition 4 directly follows from Proposition 3. Home's government has an incentive to tax resource inflows in order to reduce $\theta$ below the efficient level and to obtain pure redistribution gains via rent extraction. The government of Foreign, instead, has no incentive to deviate since, by (38), the welfare-maximizing resource tax is associated to an equilibrium in which the world resource allocation is efficient. It follows that, starting from an efficient allocation of world resource supply, the potential source of deviations is exclusively the rent-extraction mechanism for the Home country.

Now consider symmetric laissez-faire as the initial state of affairs: all taxes and subsidies are set to zero. Starting from this equilibrium, the scheme of incentives falls in three possible cases depending on the sign of productivity gaps:

Proposition 5 Given a laissez-faire equilibrium, higher RछD productivity in Home creates an incentive for Foreign to subsidize domestic resource use and exacerbates Home's incentive to tax domestic resource use. The general scheme is:

$$
\begin{array}{r}
\text { i. If } \varphi_{h}>\varphi_{f} \text { then } d U_{h} / d \tau_{h}>0 \text { and } d U_{f} / d \tau_{f}<0 ; \\
\text { ii. If } \varphi_{h}=\varphi_{f} \text { then } d U_{h} / d \tau_{h}>0 \text { and } d U_{f} / d \tau_{f}=0 ; \\
\text { iii. If } \varphi_{h}<\varphi_{f} \text { then } d U_{h} / d \tau_{h} \gtreqless 0 \text { and } d U_{f} / d \tau_{f}>0 ;
\end{array}
$$

Focusing on result (i), the intuition follows from expression (30). Higher R\&D productivity in Home implies that Home's relative resource use strictly exceeds the efficient level. In this situation, both countries have incentives to deviate. On the one hand, Foreign would gain from subsidizing domestic resource use since this would contrast Home's 
over-consumption of the resource and move the world resource allocation towards the efficiency condition $\theta=\theta_{E}$, which maximizes Foreign welfare by expression (38). On the other hand, Home would gain from taxing domestic resource use even more intensively than starting from efficiency conditions: the positive productivity gap implies that Home's resource use is strictly above the efficient level whereas maximal welfare in Home would require $\theta$ to be strictly below the efficient level by expression (39). Therefore, persistent gaps in productivity growth originating in $R \& D$ externalities matter for both countries: they create an incentive to implement subsidies in Foreign, and they exacerbate the incentive to raise taxes in Home. Since the hypothesis $\varphi_{h}>\varphi_{f}$ is empirically plausible, this conclusion suggests a novel potential explanation for the stylized facts that characterize world oil trade: the observed subsidies (taxes) on domestic oil consumption in oil-rich (oil-poor) economies may be induced by the fact that oil-poor countries exhibit faster growth in R\&D productivity with stronger spillovers from past research. ${ }^{14}$ Below, we investigate whether this explanation is supported by game-theoretic arguments.

\section{Strategic Taxation}

In this section, we extend the previous analysis to include strategic interaction between the two countries' governments. ${ }^{15}$ Our main objective is to understand whether the coexistence of resource subsidies in Foreign and resource taxes in Home can be an equilibrium outcome when both governments choose the respective resource taxes in a strategic manner. As a first step, we consider one-shot games where each government sets the

\footnotetext{
${ }^{14}$ The other cases (ii)-(iii) reported in Proposition 5 are easily interpreted. If $\mathrm{R} \& \mathrm{D}$ technologies are identical in the two countries, relative resource use coincides with the efficient level so that Proposition 4 applies. Finally, if R\&D productivity is higher in Foreign, relative resource use falls short of the efficient level: Foreign would gain from raising a resource tax whereas Home would gain by implementing either a resource tax or a subsidy, depending on the width of the productivity gap.

${ }^{15}$ The welfare-tax relationships studied in section 4 neglect strategic interactions between the two countries in the sense that implementing $\tau_{i}^{\max }$ in country $i$ maximizes domestic welfare $U_{i}$ all else equal, that is, only if the other country's tax rate is unchanged.
} 
domestic tax once and forever. After showing that no Nash equilibrium exists with simultaneous moves (subsect. 5.1), we consider two-stage games and show that the only equilibrium that may exist with finite tax rates is a Stackelberg equilibrium in which Foreign government moves first (subsect. 5.2). We then show that the unique Stackelberg equilibrium is characterized by resource subsidies in Foreign and resource taxes in Home for a wide range of parameter values (subsect. 5.3). Several interpretations of the Stackelberg equilibrium in terms of commitment devices are discussed in subsection 5.4. Throughout this section, we simplify the analysis by setting all non-resource taxes to zero.

\subsection{Nash Equilibria}

This section investigates the existence of Nash equilibria in pure strategies. We take as a benchmark a one-shot game with simultaneous moves where each government $i$ uses the domestic resource tax rate $\tau_{i}$ as an instrument to maximize own welfare $U_{i}$ given the other country's chosen tax rate $\tau_{j}$ (where index $j$ denotes the country $\neq i$ ). The chosen tax rates are then implemented from the reference 'time zero' onward. The best response function of government $i$ is $\tau_{i}^{B}=B_{i}\left(\tau_{j}\right)$, which essentially represents the domestic welfaremaximizing tax rate $\tau_{i}^{\max }$ defined in the previous section as a function $B_{i}(\cdot)$ of the other country's tax $\tau_{j}$. Given the two governments' best response functions, $\tau_{h}^{B}=B_{h}\left(\tau_{f}\right)$ and $\tau_{f}^{B}=B_{f}\left(\tau_{h}\right)$, a Nash equilibrium is a couple of values $\left(\tau_{h}^{e}, \tau_{f}^{e}\right)$ for which a fixed point exists, that is, $B_{h}\left(\tau_{f}^{e}\right)=\tau_{h}^{e}$ and $B_{f}\left(\tau_{h}^{e}\right)=\tau_{f}^{e}$. In seeking such equilibria, the only restrictions that we impose are that (i) both countries' tax rates take finite values and (ii) that such values are compatible with the existence of a market equilibrium with positive consumption. In the latter respect, we note that expression (34) determines a lower bound on Home's tax rate: a positive propensity $\bar{\sigma}_{h}^{c}>0$ requires us to impose the 
feasibility restriction ${ }^{16}$

$$
1+\tau_{h}>\frac{\gamma}{1-I_{h}}
$$

As shown in the Appendix, the two best response functions have the following characteristics. In Foreign, $\tau_{f}^{B}=B_{f}\left(\tau_{h}\right)$ is linear and the domestic tax rate $\tau_{f}^{B}$ is given by

$$
\tau_{f}^{B}=\underbrace{\frac{1-I_{h}}{1-I_{f}} \cdot\left(1+\tau_{h}\right)-1}_{B_{f}\left(\tau_{h}\right)}
$$

which infact implies an efficient relative resource use, $\bar{\theta}=\epsilon /(1-\epsilon)$. In Home, instead, the best response function $\tau_{h}^{B}=B_{h}\left(\tau_{f}\right)$ is non-linear and can be conveniently expressed by means of the inverse function, $\tau_{f}=B_{h}^{-1}\left(\tau_{h}^{B}\right)$, which reads

$$
\tau_{f}=\underbrace{\left\{\frac{1-\epsilon}{1-\epsilon+\Lambda\left(\tau_{h}^{B}\right)} \cdot \frac{\epsilon-\Lambda\left(\tau_{h}^{B}\right)}{\epsilon}\right\} \cdot \frac{1-I_{h}}{1-I_{f}} \cdot\left(1+\tau_{h}^{B}\right)-1}_{B_{h}^{-1}\left(\tau_{h}^{B}\right)},
$$

where we have defined

$$
\Lambda\left(\tau_{h}^{B}\right) \equiv \frac{1-\alpha}{\left(1+\tau_{h}^{B}\right)\left(1-I_{h}\right)-\gamma}>0
$$

The strictly positive sign of $\Lambda\left(\tau_{h}^{B}\right)$ follows from the feasibility restriction (40), and implies that the term in curly brackets in (42) is strictly below unity for any feasible finite value of $\tau_{h}^{B}$. Therefore, by comparing the right hand sides of (41) and (42), we obtain that the strict inequality

$$
B_{f}\left(\tau_{h}^{o}\right)>B_{h}^{-1}\left(\tau_{h}^{o}\right)
$$

holds for any feasible finite tax rate $\tau_{h}^{o}$. This means that no Nash equilibrium exists, in that such an equilibrium would require $B_{f}\left(\tau_{h}^{e}\right)=B_{h}^{-1}\left(\tau_{h}^{e}\right)$ for a feasible finite value $\tau_{h}^{e}$. This result is graphically described in graph (a) of Figure 1, showing the lack of intersections between the two response functions. In the same Figure, graph (b) provides

\footnotetext{
${ }^{16}$ The economic intuition for this lower bound is that a positive consumption share requires, amongst other conditions, that Home does not spend too much on imported resource inputs. In this respect, raising $\tau_{h}$ helps reducing Home's demand for resource imports, from which it follows that $\tau_{h}$ must not be too low.
} 
further intuition by interpreting this result as an everlasting tax war: a hypothetical tax rate $\tau_{h}^{\prime}$ in Home would prompt Foreign to implement the tax rate $\tau_{f}^{\prime}$, to which Home would respond with a higher tax rate $\tau_{h}^{\prime \prime}>\tau_{h}^{\prime}$, which in turn would call for a higher Foreign tax rate, and so on. As long as governments move simultaneously, their incentives remain mutually inconsistent for any combination of finite tax rates because Home's government always has an incentive to push relative resource use below the efficient level desired by Foreign. This observation naturally leads us to consider alternative one-shot games in which governments do not move simultaneously, a point which we address below.

\subsection{Stackelberg Equilibria}

Suppose that the government of one country sets the domestic resource tax before the other country's government sets its own resource tax, and that the chosen tax rates are then implemented from the reference time zero onwards. This is still a one-shot game i.e., each government sets the domestic tax once and forever - but choices are now made in two distinct stages, which makes the strategic interaction richer. The second mover, denoted by $j$, observes the tax rate chosen by the first mover $\tau_{i}$, and optimally chooses the domestic tax $\tau_{j}=\tau_{j}^{S 2}$ according to the same best-response function that we have used to study Nash equilibria, namely $\tau_{j}^{S 2}=B_{j}\left(\tau_{i}\right)$. Under complete information, the first mover expects the opponent's reaction and chooses the domestic tax $\tau_{i}=\tau_{i}^{S 1}$ that maximizes domestic welfare taking into account the best response function of the other government,

$$
\tau_{i}^{S 1}=\arg \max _{\left\{\tau_{i}\right\}} U_{i}\left(\tau_{i}, \tau_{j}^{S 2}\right)=\arg \max _{\left\{\tau_{i}\right\}} U_{i}\left(\tau_{i}, B_{j}\left(\tau_{i}\right)\right) .
$$

A Stackelberg equilibrium is a couple of feasible finite values $\left(\tau_{i}^{S 1}, \tau_{j}^{S 2}\right)$ that jointly satisfy the two players' optimality conditions - that is, $\tau_{j}^{S 2}=B_{j}\left(\tau_{i}^{S 1}\right)$ and

$$
\left.\frac{\mathrm{d} U_{i}\left(\tau_{i}, B_{j}\left(\tau_{i}\right)\right)}{\mathrm{d} \tau_{i}}\right|_{\tau_{i}=\tau_{i}^{S 1}}=0 .
$$

Below, we study the existence of Stackelberg equilibria in the two possible scenarios, namely the one in which Home is the leader and the other in which Home is the follower. To derive neat results, we re-write the welfare levels (32)-(33) as functions of both 
countries' tax rates as follows (see Appendix):

$$
\begin{aligned}
& U_{h}\left(\tau_{h}, \tau_{f}\right)=\tilde{\varkappa}_{h}+\Gamma\left(\bar{\theta}\left(\tau_{h}, \tau_{f}\right)\right)+\frac{1}{\rho} \ln \left[1-I_{f}-\frac{\gamma}{1+\tau_{h}}\right], \\
& U_{f}\left(\tau_{h}, \tau_{f}\right)=\tilde{\varkappa}_{f}+\Gamma\left(\bar{\theta}\left(\tau_{h}, \tau_{f}\right)\right)+\frac{1}{\rho} \ln \left[1-I_{f}+\frac{\gamma}{1+\tau_{h}} \cdot \frac{\epsilon}{1-\epsilon} \cdot \frac{1-I_{f}}{1-I_{h}}\right],
\end{aligned}
$$

where $\tilde{\varkappa}_{i}$ are country-specific constants, the last terms in square brackets equal the respective consumption propensities $\bar{\sigma}_{i}^{c}$, and the term

$$
\Gamma(\bar{\theta}) \equiv \frac{1}{\rho} \cdot \frac{\gamma}{1-\alpha} \ln \left(\frac{\bar{\theta}^{\epsilon}}{1+\bar{\theta}}\right)
$$

depends on both countries' resource taxes $\left(\tau_{h}, \tau_{f}\right)$ through the equilibrium level of $\bar{\theta}$, given by (26). This new formulation of welfare curves yields an intuitive characterization of Stackelberg equilibria, as shown below.

I. Home moves first: Suppose that Home's government moves first by choosing a tax rate $\tau_{h}$. At the second stage, Foreign government observes $\tau_{h}$ and reacts by setting the tax rate

$$
\tau_{f}^{S 2}=B_{f}\left(\tau_{h}\right)
$$

which is the welfare-maximizing rate $\tau_{f}^{\max }$ given $\tau_{h}$. By Proposition 3, any situation in which $\tau_{f}=\tau_{f}^{\max }$ necessarily implies an efficient level of relative resource use $\bar{\theta}=\epsilon /(1-\epsilon)$. Substituting this outcome in (45), we obtain the welfare function that is relevant for Home's government at the first stage:

$$
U_{h}\left(\tau_{h}, \tau_{f}^{S 2}\right)=\tilde{\varkappa}_{h}+\Gamma\left(\frac{\epsilon}{1-\epsilon}\right)+\frac{1}{\rho} \ln \left[1-I_{f}-\frac{\gamma}{1+\tau_{h}}\right]
$$

which depends on $\tau_{h}$ exclusively through the last term in square brackets, which represents Home's consumption propensity. Since $U_{h}\left(\tau_{h}, \tau_{f}^{S 2}\right)$ is concave but always strictly increasing in $\tau_{h}$, the only optimal choice for Home as a leader would be to set $\tau_{h}^{S 1}=+\infty$. The intuition is that when Foreign is the last mover, relative resource use is stuck at the efficient level and the only instrument that Home has to increase its own utility in the first stage is to maximize rent extraction indefinitely, eventually using an infinite tax rate. However, this solution would call for an infinite Foreign tax rate too, in view of the 
best-response function (41). Hence, when Home moves first, no Stackelberg equilibrium with finite tax rates exists. Interestingly, this conclusion is radically overturned when the leader is Foreign government, as shown below.

II. Foreign moves first: Suppose that Foreign' government moves first by choosing a tax rate $\tau_{f}$. At the second stage, Home's government observes $\tau_{f}$ and reacts by setting the tax rate

$$
\tau_{h}^{S 2}=B_{h}\left(\tau_{f}\right)
$$

which corresponds to the welfare-maximizing rate $\tau_{h}^{\max }$ given $\tau_{f}$. By Proposition 3, any situation in which $\tau_{h}=\tau_{h}^{\max }$ necessarily implies that the equilibrium level of relative resource use is inefficiently low. More precisely, as shown in the Appendix, the equilibrium level $\bar{\theta}=\theta^{S 2}$ induced by Home's reaction to the Foreign tax rate $\tau_{f}$ is

$$
\theta^{S 2}\left(\tau_{f}\right)=\frac{\epsilon-\Lambda\left(B_{h}\left(\tau_{f}\right)\right)}{1-\epsilon+\Lambda\left(B_{h}\left(\tau_{f}\right)\right)}, \quad \frac{\mathrm{d} \theta^{S 2}\left(\tau_{f}\right)}{\mathrm{d} \tau_{f}}>0,
$$

where both the functions $B_{h}(\cdot)$ and $\Lambda(\cdot)$ are defined in expression (42) above. The intuition behind the result $\mathrm{d} \theta^{S 2} / \mathrm{d} \tau_{f}>0$ is that a higher Foreign tax rate (which, without Home's reaction, would raise relative resource use) prompts Home's government to increase its own tax rate in order to keep relative resource use at the desired, inefficiently low level. Combining these outcomes with expression (46), we obtain the welfare function that is relevant for the Foreign' government in the first stage:

$$
U_{f}\left(B_{h}\left(\tau_{f}\right), \tau_{f}\right)=\tilde{\varkappa}_{f}+\Gamma\left(\theta^{S 2}\left(\tau_{f}\right)\right)+\frac{1}{\rho} \ln \left[1-I_{f}+\frac{\gamma}{1+B_{h}\left(\tau_{f}\right)} \cdot \frac{\epsilon}{1-\epsilon} \cdot \frac{1-I_{f}}{1-I_{h}}\right] .
$$

Expression (49) shows that the choice of $\tau_{f}$ at the first stage affects Foreign' welfare through two channels. On the one hand, choosing a higher $\tau_{f}$ induces a higher relative resource use $\theta^{S 2}\left(\tau_{f}\right)$ via Home's reaction, as established in (48). On the other hand, choosing a higher $\tau_{f}$ induces a higher tax in Home $\tau_{h}^{S 2}=B_{h}\left(\tau_{f}\right)$ which reduces Foreign' consumption propensity, as shown by the term in square brackets. These two effects push welfare $U_{f}$ in opposite directions: the increase in $\theta^{S 2}\left(\tau_{f}\right)$ is always welfare-improving because relative resource use gets closer to (without ever reaching) the efficient level 
desired by Foreign ${ }^{17}$, whereas the reduction in Foreign' consumption propensity reduces present-value utility. The combination of these effects implies that $U_{f}\left(B_{h}\left(\tau_{f}\right), \tau_{f}\right)$ may be a hump-shaped function of $\tau_{f}$ and, hence, display a unique maximum associated to a finite tax rate $\tau_{f}^{S 1}$. In the Appendix, we establish several properties of $U_{f}\left(B_{h}\left(\tau_{f}\right), \tau_{f}\right)$, including

$$
\frac{\mathrm{d} \Gamma\left(\theta^{S 2}\left(\tau_{f}\right)\right)}{\mathrm{d} \tau_{f}}>0 \text { and } \quad \frac{\mathrm{d} \bar{\sigma}_{f}^{c}\left(B_{h}\left(\tau_{f}\right)\right)}{\mathrm{d} \tau_{f}}<0 .
$$

As a consequence of (50), the total derivative of the welfare function (49) includes one positive and one negative term, namely

$$
\frac{\mathrm{d}}{\mathrm{d} \tau_{f}} U_{f}\left(B_{h}\left(\tau_{f}\right), \tau_{f}\right)=\underbrace{\frac{\mathrm{d}}{\mathrm{d} \tau_{f}} \Gamma\left(\theta^{S 2}\left(\tau_{f}\right)\right)}_{\text {Positive }}+\underbrace{\frac{1}{\rho} \frac{\mathrm{d}}{\mathrm{d} \tau_{f}} \ln \bar{\sigma}_{f}^{c}\left(B_{h}\left(\tau_{f}\right)\right)}_{\text {Negative }}
$$

so that it is generally possible to satisfy the first order condition

$$
\frac{\mathrm{d}}{\mathrm{d} \tau_{f}} U_{f}\left(B_{h}\left(\tau_{f}\right), \tau_{f}\right)=0
$$

The existence and uniqueness of an interior maximum satisfying (52) can be verified numerically by assuming different combinations of parameter values. In this respect, all our numerical simulations show that $U_{f}\left(B_{h}\left(\tau_{f}\right), \tau_{f}\right)$ is infact hump-shaped and thus exhibits a unique, finite $\tau_{f}^{S 1}$ such that (52) holds. Figure 2, graph (a), depicts five examples obtained by varying the values taken by $R \& D$ productivities $\left(\varphi_{h}, \varphi_{f}\right)$, the value of the taste parameter for Home goods $(\epsilon)$, the values of production shares of intermediate goods $(\alpha)$ and of the resource $(\gamma)$. The diagrams show that a unique maximum point exists in each case so that both $\tau_{f}^{S 1}$ and the associated response $\tau_{h}^{S 2}=B_{h}\left(\tau_{f}^{S 1}\right)$ are finite. Since this result regularly holds in all our simulations (beyond the five examples reported in Figure 2), we conclude that

Proposition 6 When Foreign is the first mover, there exists a unique Stackelberg equilibrium $\left(\tau_{f}^{S 1}, \tau_{h}^{S 2}\right)$ with finite tax rates for a wide range of parameter values.

\footnotetext{
${ }^{17}$ This statement is formally proved in the Appendix: see expressions (A.66)-(A.67).
} 
Since we have shown that no Nash equilibrium exists and that no Stackelberg equilibrium exists when Home's government is the leader, Proposition 6 defines the benchmark result for discussing behavioral predictions. In particular, assuming the existence of a commitment device that forces governments to rule out infinite tax rates - which may take the form of different mechanisms, as we argue in subsection 5.4 below - the only feasible equilibrium appears to be a Stackelberg equilibrium in which Foreign sets a finite

$\operatorname{tax}$ rate $\tau_{f}^{S 1}$ and Home sets the welfare-maximizing tax rate $\tau_{h}^{S 2}$ that implements the desired, inefficiently low level of relative resource use. Before discussing the interpretation of this result, we determine under what circumstances the Stackelberg equilibrium is characterized by subsidies in Foreign along with positive taxes in Home.

\subsection{Foreign Subsidies and Equilibrium Outcomes}

A key motivation of our analysis is the lack of theoretical arguments explaining why oil-rich countries subsidize domestic oil use while oil-poor economies typically tax oil imports. The central question is thus whether these policies can be rationalized as a strategic equilibrium outcome. Proposition 6 suggests one possible interpretation, namely that governments obey a Stackelberg equilibrium $\left(\tau_{f}^{S 1}, \tau_{h}^{S 2}\right)$ where

$$
\tau_{f}^{S 1}<0 \text { and } \tau_{h}^{S 2}>0
$$

There are indeed circumstances in which the inequalities (53) hold. Suppose that the initial state of affairs is a laissez-faire equilibrium, and that the Home economy displays a higher R\&D productivity, $\varphi_{h}>\varphi_{f}$. We know from Proposition 5 that, in the absence of strategic interactions, Foreign is tempted to subsidize whereas Home is tempted to tax domestic resource use. In the Stackelberg game with strategic interaction, we obtain the following results.

Assuming that Foreign moves first, all the numerical simulations we performed show that $\tau_{h}^{S 2}>0$ generally holds whereas the sign of $\tau_{f}^{S 1}$ is crucially determined by the taste parameter $\epsilon$ according to a negative relationship: the higher is the taste for Home final goods in household preferences, the lower is $\tau_{f}^{S 1}$. For $\epsilon$ sufficiently high, the Stackelberg 
equilibrium is characterized by the inequalities (53). The example reported in Graph (b) of Figure 2 depicts four welfare curves $\left(u^{\prime}, u^{\prime \prime}, u^{\prime \prime \prime}, u^{\prime \prime \prime \prime}\right)$ respectively obtained by imposing $\epsilon=(0.50,0.55,0.60,0.65)$ while holding all other parameters fixed. ${ }^{18}$ The resulting equilibria exhibit $\tau_{f}^{S 1}=(0.11,-0.23,-0.48,-0.66)$ and $\tau_{h}^{S 2}=(1.63,1.16,0.80,0.51)$. Hence, in this example, all the values $\epsilon>1 / 2$ determine Stackelberg equilibria in which Foreign imposes a subsidy whereas Home levies a positive resource tax. Similar results hold in all other simulations (not reported here), which leads us to conclude that

Proposition 7 Starting from a laissez-faire situation with a productivity gap $\varphi_{h}>\varphi_{f}$, if the taste for Home final goods $\epsilon$ is sufficiently high, the Stackelberg equilibrium is characterized by a resource subsidy $\tau_{f}^{S 1}<0$ in Foreign and a resource taxe $\tau_{h}^{S 2}>0$ in Home.

In all our simulations (not reported here), the threshold level of $\epsilon$ above which $\tau_{f}^{S 1}$ turns negative tends to fall between 0.50 and 0.55 . We note that $\epsilon>1 / 2$ is empirically plausible because resource-poor countries with high $R \& D$ productivity typically produce consumption goods that capture higher shares of household consumption relative to the final goods produced by resource-rich economies displaying low R\&D productivity.

\subsection{Interpretation and Extensions}

In order to interpret the Stackelberg equilibrium as a behavioral prediciton, there must be a commitment device ensuring that both countries indeed choose $\left(\tau_{f}^{S 1}, \tau_{h}^{S 2}\right)$. The most evident argument is suggested by the fact that, if infinite tax rates are excluded by both governments, then no Nash equilibrium exists and the only Stackelberg equilibrium is the one in which Foreign moves first. If infinite tax rates are ruled out ex-ante, we can thus imagine a one-shot game where each government is able to choose between 'being the leader', 'being the follower', or 'move simultaneously', and conclude that the only feasible

\footnotetext{
${ }^{18}$ The other parameter values used to obtain the examples shown in graph (b) of Figure 2 are: $\rho=0.04$, a productivity gap $\varphi_{h} / \varphi_{f}$ implying a $15 \%$ difference in investment rates with $I_{h}=0.05$ and $I_{f}=0.0425$, $\alpha=0.5, \gamma=0.03$. Variations in these parameter values do not qualitatively affect our results.
} 
equilibrium is $\left(\tau_{f}^{S 1}, \tau_{h}^{S 2}\right)$. This reasoning is fairly general as it goes beyond the question of which specific device actually induces both governments' commitment. The natural extension of this reasoning concerns the existence of self-enforcing commitment devices when the taxation game is not one-shot but is rather a repeated one. In this respect, the literature on repeated games suggests that a case of direct interest to our analysis is the theory of 'wars of attrition' (Fudenberg and Tirole, 1991: Chapter 4). In this framework, the players' payoffs include the expected costs of responding indefinitely to the opponent's sequence of moves, which leads to an equilibrium where both players set their choice variable in a forward looking manner and do not modify it afterwords. This suggests - recalling our previous results on everlasting wars in Figure 1 - that extending our tax game to include the expected (e.g.) political costs of modifying resource taxes over time should create strategic equilibria with finite tax rates in view of a commitment device endogenously determined by political costs. Tackling this issue is an interesting topic for future research.

Another point that deserves further scrutiny is how national strategies may be affected in a multi-country environment where large and small countries coexist. In this paper, we have considered national governments that are able to foresee the reaction of terms of trade to their domestic tax policies. Introducing small price-taking countries in the picture would create interactions with the strategies pursued by big trading economies, which would open the door to further results in policy outcomes.

\section{Conclusion}

Asymmetric trade structures may provide national governments with different types of incentives to enact strategic taxes at the national level. Our analysis shows that, introducing endogenous growth in a two-country model with uneven resource endowments, structural gaps in productivity growth create asymmetric incentives to deviate from laissez-faire equilibria. Stronger spillovers from past research in resource-poor economies exacerbate the importers' willingness to tax resource use while prompting exporters to subsidize do- 
mestic consumption independently of the rent-extraction mechanism. In a strategic tax game, the only equilibrium is of Stackelberg type and features, for a wide range of parameter values, positive exporters' subsidies and positive importers' taxes at the same time. This scenario is consistent with the stylized facts that characterize world oil trade and, in our view, deserves further scrutiny at both the theoretical and the empirical levels. More generally, the argument that growth differentials matter for strategic trade policies is under-researched but highly relevant for policymaking, so that further research in this direction is certainly desirable.

\section{References}

Amundsen, Eirik S. and Ronnie Schöb (1999) Environmental taxes on exhaustible resources. European Journal of Political Economy 15, 311-329.

Aznar-Marquez, Juana and José Ramón Ruiz-Tamarit (2005) Renewable natural resources and endogenous growth. Macroeconomic Dynamics 9, 170-197.

Barro, Robert J. and Xavier Sala-i-Martin (2004) Economic Growth. Second Edition. Cambdridge MA: MIT Press.

Bergstrom, Theodore C. (1982) On Capturing Oil Rents with a National Excise Tax. American Economic Review 72, 194-201.

Brander, James and Slobodan Djajic (1983). Rent-Extracting Tariffs and the Management of Exhaustible Resources. Canadian Journal of Economics 16, 288-298.

Bretschger, Lucas and Simone Valente (2012). Endogenous Growth, Asymmetric Trade and Resource Dependence. Journal of Environmental Economics 63 Management $64,301-311$.

Bretschger, Lucas and Simone Valente (2016). Productivity Gaps under Asymmetric Trade. CER-ETH Center of Economic Research Working Paper 16/239, ETH Zürich. 
Daubanes, Julien and André Grimaud (2010). Taxation of a Polluting Non-renewable Resource in the Heterogeneous World. Environmental and Resource Economics 47, $567-588$.

Feenstra, Robert C. (1996). Trade and uneven growth. Journal of Development Economics 49, 229-256.

Fudenberg, Drew and Jean Tirole (1991). Game Theory. Cambdridge MA: MIT Press.

Grossman, Gene M. and Elhanan Helpman (1990). Comparative Advantage and Longrun Growth. American Economic Review 80, 796-815.

Gupta, S., Clements, B., Fletcher, K., Inchauste, G. (2002). Issues in Domestic Petroleum Pricing in Oil-Producing Countries. IMF Working Paper WP/02/140, International Monetary Fund.

Lederman, Daniel and William F. Maloney (2007). Natural Resources - Neither Curse Nor Destiny. The World Bank, Washington DC.

Liski, Matti and Olli Tahvonen (2004). Can carbon tax eat OPEC's rents. Journal of Environmental Economics and Management 47, 1-12.

Metschies, Gerhard P. (2005). International Fuel Prices 2005. GTZ - Federal Ministry for Economic Cooperation and Development: Eschborn.

Peretto, Pierto F. (2012). Resource abundance, growth and welfare: A Schumpeterian perspective. Journal of Development Economics 97, 142-155.

Peretto, Pietro F. ans Simone Valente, S. (2011). Resources, Innovation and Growth in the Global Economy. Journal of Monetary Economics 58, 387-399.

Rivera-Batiz, Luis A. and Paul Romer (1991). Economic Integration and Endogenous Growth. Quarterly Journal of Economics 106, 531-555.

Robinson, James A., Ragnar Torvik and Thierry R. Verdier (2006). Political foundations of the resource curse. Journal of Development Economics 79, 447-468. 
Rubio, Santiago J. and Luisa Escriche (2001). Strategic pigouvian taxation, stock externalities and non-renewable resources. Journal of Public Economics 79, 297-313.

Tornell, Aaron and Philip R. Lane (1999). The Voracity Effect. American Economic Review 89, 22-46.

Valente, Simone (2009). International status seeking, trade, and growth leadership. Canadian Journal of Economics 42, 554-589.

Valente, Simone (2011). Endogenous Growth, Backstop Technology Adoption, and Optimal Jumps. Macroeconomic Dynamics 15, 293-325.

WTO (2011). World Trade Report 2010 - Trade in natural resources. Geneve: WTO Publications. 


\section{A Appendix}

This appendix contains the main proofs and derivations. Further proofs and detailed derivations are available on-line as Supplementary Material.

Monopoly rents. Maximization of $\Pi_{i}\left(m_{i}\right)=\left(P_{X\left(m_{i}\right)}^{i}-\varsigma P_{Y}^{i}\right) \cdot X_{i}\left(m_{i}\right)$ s.t. (3) gives

$$
\begin{aligned}
& X_{i}\left(m_{i}\right)=X_{i}=\left\{\alpha^{2}\left(v_{i} L_{i}\right)^{\beta} R_{i}^{\gamma}\left[\varsigma\left(1+b_{i}\right)\right]^{-1}\right\}^{\frac{1}{1-\alpha}}, \\
& \Pi_{i}\left(m_{i}\right)=\Pi_{i}=(1-\alpha) P_{X}^{i} X_{i} .
\end{aligned}
$$

Substituting (A.1) in (3) yields (4). For future reference, expressions (A.1) and (1) imply

$$
Y_{i}=\left(\alpha^{2} / \varsigma\right)^{\frac{\alpha}{1-\alpha}} \cdot\left[1+b_{i}\right]^{-1} \cdot M_{i}\left(v_{i} L_{i}\right)^{\frac{\beta}{1-\alpha}}\left(R_{i}\right)^{\frac{\gamma}{1-\alpha}}
$$

$\mathbf{R} \& \mathbf{D}$ sector. Denoting by $V_{i}$ the value of a patent, the zero-profit condition is ${ }^{19}$

$$
V_{i}=P_{Y}^{i} /\left[\phi_{i}\left(1+a_{i}\right)\right]
$$

Denoting by $r_{i}$ the interest rate in country $i$, the no-arbitrage condition is

$$
r_{i}(t) V_{i}(t)=\Pi_{i}(t)+\dot{V}_{i}(t),
$$

Derivation of (9)-(10). Maximize (8) subject to $\dot{Q}=-R$ using the Hamiltonian $P_{R} R-\chi R$, where $\chi$ is the dynamic multiplier. The optimality conditions read

$$
\begin{aligned}
P_{R}(t) & =\chi(t), \\
\dot{\chi}(t) & =r_{f}(t) \chi(t), \\
\lim _{t \rightarrow \infty} \chi(t) Q(t) e^{-\int_{t}^{\infty} r_{f}(v) d v} & =0,
\end{aligned}
$$

Plugging (A.6) in (A.7), we have (9). Integrating (A.7) and substituting the resulting expression in (A.8), we have $\lim _{t \rightarrow \infty} \chi(0) Q(t)=0$, which implies $\lim _{t \rightarrow \infty} Q(t)=0$. Integrating $\dot{Q}(t)=-R(t)$ between time zero and infinity thus yields (10).

\footnotetext{
${ }^{19}$ Aggregate profits of the R\&D sector equal $V_{i} \dot{M}_{i}-P_{Y}^{i} Z_{i}=V_{i} \phi_{i} Z_{i}\left(1+a_{i}\right)-P_{Y}^{i} Z_{i}$, so that condition (A.4) maximizes R\&D profits for a given marginal productivity $\phi_{i}$. Condition (A.4) can be equivalently obtained assuming free entry in the R\&D business (see Barro and Sala-i-Martin, 2004).
} 
Consumer problem (step 1). Maximization of (12) s.t. (13) implies

$$
\begin{aligned}
c_{i}^{f} / c_{i}^{h} & =\frac{1-\epsilon}{\epsilon}\left(P_{Y}^{h} / P_{Y}^{f}\right), \\
P_{Y}^{h} c_{i}^{h} & =\epsilon \cdot E_{i}^{c} / L_{i} \text { and } P_{Y}^{f} c_{i}^{f}=(1-\epsilon) \cdot E_{i}^{c} / L_{i}, \\
\bar{u}_{i} & =\ln \left\{\left[\frac{\epsilon}{\left(P_{Y}^{h}\right)^{\epsilon}\left(P_{Y}^{f}\right)^{1-\epsilon}}\left(\frac{1-\epsilon}{\epsilon}\right)^{1-\epsilon}\right] \cdot E_{i}^{c} / L_{i}\right\},
\end{aligned}
$$

where (A.9) holds in each country $i=h, f$, expressions (A.10) follow from plugging (A.9) in (13), and expression (A.11) follows from substituting (A.10) in (12). Denoting the term in square brackets in $(\mathrm{A} .11)$ as $\omega=\omega\left(P_{Y}^{h}, P_{Y}^{f}\right)$, indirect utility is $\bar{u}_{i}=\ln \left[\omega \cdot\left(E_{i}^{c} / L_{i}\right)\right]$ in each country $i=h, f$.

Consumer problem (step 2). Individual wealth is $\left(1 / L_{i}\right)$ times the value of all domestic assets $V_{i} M_{i}$. Defining $n_{i} \equiv\left(V_{i} M_{i}\right) / L_{i}$, the wealth constraints read

$$
\begin{aligned}
& \dot{n}_{h}=r_{h} n_{h}+P_{L}^{h}-\left(E_{h}^{c} / L_{h}\right)-F_{h}, \\
& \dot{n}_{f}=r_{f} n_{f}+P_{L}^{f}-\left(E_{f}^{c} / L_{f}\right)-F_{f}+P_{R}\left(R / L_{f}\right),
\end{aligned}
$$

where $r_{i} n_{i}+P_{L}^{i}$ is income from assets and labor in country $i$, and $P_{R}\left(R / L_{f}\right)$ is resource income for each Foreign resident. Agents in country $i$ maximize (14) subject to the relevant constraint, (A.12) or (A.13), using consumption expenditure $\left(E_{i}^{c} / L_{i}\right)$ as control variable. Denoting by $\lambda_{i}$ the multiplier, the optimality conditions $L_{i} / E_{i}=\lambda_{i}$ and $\dot{\lambda}_{i}=$ $\lambda_{i}\left(\rho-r_{i}\right)$ imply (15).

Derivation of (19). From (A.2) and (A.4), we have

$$
\frac{\Pi_{i}}{V_{i}}=\phi_{i} \frac{\left(1+a_{i}\right)(1-\alpha) P_{X}^{i} X_{i}}{P_{Y}^{i}}=\varphi_{i} \cdot \frac{\left(1+a_{i}\right)(1-\alpha) \alpha}{1+b_{i}},
$$

where the last term follows from substituting $\phi_{i}$ by (6) and $\left(P_{X}^{i} M_{i} X_{i}\right) /\left(P_{Y}^{i} Y_{i}\right)=$ $\alpha /\left(1+b_{i}\right)$ by (3). Equations (A.4) and (6) yield $V_{i}=\left(P_{Y}^{i} Y_{i}\right) /\left[\varphi_{i} \cdot M_{i}\left(1+a_{i}\right)\right]$, so that

$$
\hat{V}_{i}(t)=\hat{P}_{Y}^{i}+\hat{Y}_{i}-\hat{M}_{i}
$$

Substituting (A.14) and (A.15) in (A.5), we get

$$
r_{i}=\varphi_{i} \alpha(1-\alpha)\left(1+a_{i}\right)\left(1+b_{i}\right)^{-1}+\hat{P}_{Y}^{i}+\hat{Y}_{i}-\hat{M}_{i}
$$


Time-differentiation of (A.3) yields

$$
\hat{Y}_{i}=\hat{M}_{i}+\frac{\beta}{1-\alpha} \eta_{i}+\frac{\gamma}{1-\alpha} \hat{R}_{i}
$$

Plugging (A.17) in (A.16), we obtain equation (19).

Propensities to spend. For future reference, define the propensities

$$
\bar{\sigma}_{i}^{c} \equiv E_{i}^{c} /\left(P_{Y}^{i} Y_{i}\right), \quad \bar{\sigma}_{i}^{d} \equiv E_{i}^{d} /\left(P_{Y}^{i} Y_{i}\right), \quad \bar{\sigma}_{i}^{x} \equiv E_{i}^{x} /\left(P_{Y}^{i} Y_{i}\right)
$$

Two equilibrium relationships characterize both countries. First, from (4), we have $\bar{\sigma}_{i}^{x}=$ $\left(P_{Y}^{i} \varsigma M_{i} X_{i}\right) /\left(P_{Y}^{i} Y_{i}\right)=\alpha\left(P_{X}^{i} M_{i} X_{i}\right) /\left(P_{Y}^{i} Y_{i}\right)$, where we can substitute $\left(P_{X}^{i} M_{i} X_{i}\right) /\left(P_{Y}^{i} Y_{i}\right)=$ $\alpha /\left(1+b_{i}\right)$ from (3) to obtain

$$
\bar{\sigma}_{i}^{x}=E_{i}^{x} /\left(P_{Y}^{i} Y_{i}\right)=\alpha^{2}\left(1+b_{i}\right)^{-1} \quad \text { for each } i=h, f .
$$

Second, from (15), the growth rate of $\bar{\sigma}_{i}^{c} \equiv E_{i}^{c} /\left(P_{Y}^{i} Y_{i}\right)$ equals

$$
\widehat{\bar{\sigma}}_{i}^{c}=r_{i}(t)-\rho-\hat{P}_{Y}^{i}-\hat{Y}_{i}=\varphi_{i} \alpha(1-\alpha)\left(1+a_{i}\right)\left(1+b_{i}\right)^{-1}-\hat{M}_{i}-\rho,
$$

where we have substituted $r_{i}$ by (A.16). Plugging $E_{i}^{d} \equiv P_{Y}^{i} Z_{i}\left(1+a_{i}\right)$ in (7) and using $\bar{\sigma}_{i}^{d} \equiv E_{i}^{d} /\left(P_{Y}^{i} Y_{i}\right)$, the growth rate of varieties equals $\hat{M}_{i}=\varphi_{i} \bar{\sigma}_{i}^{d}$, which can be substituted in the above expression to obtain

$$
\widehat{\bar{\sigma}}_{i}^{c}=\varphi_{i} \alpha(1-\alpha)\left(1+a_{i}\right)\left(1+b_{i}\right)^{-1}-\varphi_{i} \bar{\sigma}_{i}^{d}-\rho \quad \text { for each } i=h, f
$$

Derivation of (20). Consider Home. Using (A.18), and defining $\tilde{\gamma}_{h} \equiv \gamma\left(1+\tau_{h}\right)^{-1}$, we can write (17) as

$$
\bar{\sigma}_{h}^{c}+\bar{\sigma}_{h}^{d}+\bar{\sigma}_{h}^{x}=1-\left(P_{R} R_{h}\right) /\left(P_{Y}^{h} Y_{h}\right)=1-\tilde{\gamma}_{h},
$$

where the last term follows from (2). A standard stability analysis based on (A.20) shows that $\bar{\sigma}_{h}^{c}$ and $\bar{\sigma}_{h}^{d}$ are constant and equal to (see proofs in the Supplementary Material)

$$
\begin{aligned}
& \bar{\sigma}_{h}^{c}=\left(1-\tilde{\gamma}_{h}\right)-\frac{\varphi_{h}\left[\alpha(1-\alpha)\left(1+a_{h}\right)+\alpha^{2}\right]-\rho\left(1+b_{h}\right)}{\varphi_{h}\left(1+b_{h}\right)}, \\
& \bar{\sigma}_{h}^{d}=1-\tilde{\gamma}_{h}-\bar{\sigma}_{h}^{c}-\bar{\sigma}_{h}^{x}=\frac{\varphi_{h} \alpha(1-\alpha)\left(1+a_{h}\right)-\rho\left(1+b_{h}\right)}{\varphi_{h}\left(1+b_{h}\right)} .
\end{aligned}
$$


Given (A.18), constant values of $\left(\bar{\sigma}_{h}^{c}, \bar{\sigma}_{h}^{d}, \bar{\sigma}_{h}^{x}\right)$ imply that $P_{Y}^{h} Y_{h}$ grows at the same rate as all expenditure shares, $\hat{E}_{h}^{c}=\hat{E}_{h}^{d}=\hat{E}_{h}^{x}$. From (17) and (2), the ratio

$$
E_{h} / P_{Y}^{h} Y_{h}=\left(1-\tilde{\gamma}_{h}\right)
$$

is constant, so that Home's growth rate is determined by the Keynes-Ramsey rule (15):

$$
\hat{E}_{h}=\hat{E}_{h}^{c}=\hat{P}_{Y}^{h}+\hat{Y}_{h}=r_{h}-\rho .
$$

Now use (A.10) to eliminate $P_{Y}^{f} c_{h}^{f}$ and $P_{Y}^{h} c_{f}^{h}$ from (16), obtaining

$$
P_{R} R_{h}+(1-\epsilon) E_{h}^{c}=\epsilon E_{f}^{c}
$$

Substituting $P_{R} R_{h}=\tilde{\gamma}_{h} P_{Y}^{h} Y_{h}$ from (2), and $E_{h}^{c}=\bar{\sigma}_{h}^{c} P_{Y}^{h} Y_{h}$ from (A.18), we get

$$
E_{f}^{c}=\frac{1}{\epsilon}\left[\tilde{\gamma}_{h}+(1-\epsilon) \bar{\sigma}_{h}^{c}\right] \cdot P_{Y}^{h} Y_{h},
$$

where the term in square brackets is constant, implying that $E_{f}^{c} /\left(P_{Y}^{h} Y_{h}\right)$ is constant. Since $P_{Y}^{h} Y_{h}$ grows at the same rate as $E_{h}^{c}$ by (A.25), we have $\hat{E}_{f}^{c}=\hat{E}_{h}^{c}$. By the KeynesRamsey rules (15), this implies $r_{h}=r_{f}$. Imposing $r_{h}=r_{f}$ in (19) yields (20).

Derivation of (21). Combining the conditions (2) for Home and Foreign, we obtain

$$
\theta(t)=\frac{R_{h}(t)}{R_{f}(t)}=\frac{\tilde{\gamma}_{h}}{\tilde{\gamma}_{f}} \cdot \frac{P_{Y}^{h}(t) Y_{h}(t)}{P_{Y}^{f}(t) Y_{f}(t)} \text { in each } t \in[0, \infty),
$$

where $\tilde{\gamma}_{i} \equiv \gamma\left(1+\tau_{i}\right)^{-1}$ is the tax-adjusted resource elasticity in final production. Using the definition $R_{h}=\theta R_{f}$ and condition (2) for country $i=f$, constraint (18) implies

$$
E_{f}=P_{Y}^{f} Y_{f}+P_{R} R_{h}=P_{Y}^{f} Y_{f}+\theta P_{R} R_{f}=P_{Y}^{f} Y_{f}\left(1+\tilde{\gamma}_{f} \theta\right)
$$

Recalling definitions (A.18), result (A.29) and the central term in (18) imply $\bar{\sigma}_{f}^{c}+\bar{\sigma}_{f}^{x}+\bar{\sigma}_{f}^{d}=$ $1+\tilde{\gamma}_{f} \theta$, where we can substitute $\bar{\sigma}_{f}^{x}=\alpha^{2}\left(1+b_{f}\right)^{-1}$ from (A.19) to obtain

$$
\bar{\sigma}_{f}^{d}=1+\tilde{\gamma}_{f} \theta-\frac{\alpha^{2}}{1+b_{f}}-\bar{\sigma}_{f}^{c}
$$

Plugging (A.30) in (A.20) for country $i=f$ we obtain

$$
\widehat{\bar{\sigma}_{f}^{c}}=\varphi_{f} \frac{\alpha(1-\alpha)\left(1+a_{f}\right)}{1+b_{f}}-\varphi_{f}\left[1+\tilde{\gamma}_{f} \theta-\frac{\alpha^{2}}{1+b_{f}}-\bar{\sigma}_{f}^{c}\right]-\rho .
$$


Dividing both sides of (A.27) by $P_{Y}^{f} Y_{f}$ and solving for $\bar{\sigma}_{f}^{c} \equiv E_{f}^{c} /\left(P_{Y}^{f} Y_{f}\right)$, we obtain

$$
\bar{\sigma}_{f}^{c}=\frac{1}{\epsilon}\left[\tilde{\gamma}_{h}+(1-\epsilon) \bar{\sigma}_{h}^{c}\right] \cdot \frac{P_{Y}^{h} Y_{h}}{P_{Y}^{f} Y_{f}}=\frac{1}{\epsilon}\left[\tilde{\gamma}_{h}+(1-\epsilon) \bar{\sigma}_{h}^{c}\right] \cdot \frac{\tilde{\gamma}_{f}}{\tilde{\gamma}_{h}} \theta,
$$

where we have used (A.28) to get the last term. Next, define

$$
\chi \equiv \frac{1}{\epsilon}+\frac{1-\epsilon}{\epsilon} \cdot \frac{\bar{\sigma}_{h}^{c}}{\tilde{\gamma}_{h}}>1
$$

Since $\bar{\sigma}_{h}^{c}$ is constant by (A.22), $\chi$ is also constant and (A.32) implies

$$
\bar{\sigma}_{f}^{c}=\chi \tilde{\gamma}_{f} \theta \text { and } \widehat{\bar{\sigma}_{f}^{c}}=\hat{\theta}
$$

Substituting the second expression in (A.34) into (A.31) we obtain

$$
\hat{\theta}(t)=\varphi_{f}(\chi-1) \tilde{\gamma}_{f} \cdot \theta(t)+\varphi_{f}\left[\alpha(1-\alpha)\left(1+a_{f}\right)+\alpha^{2}\right]\left(1+b_{f}\right)^{-1}-\left(\varphi_{f}+\rho\right) .
$$

Since $\varphi_{f}(\chi-1) \tilde{\gamma}_{f}>0$, equation (A.35) is globally unstable around $\hat{\theta}(t)=0$. Ruling out explosive dynamics implying unbounded propensities to consume in Foreign, we have $\theta(t)=\bar{\theta}$ in each $t \in[0, \infty)$, where $\bar{\theta}$ is the steady-state level in (A.35):

$$
\bar{\theta} \equiv \frac{\left(\varphi_{f}+\rho\right)\left(1+\tau_{f}\right)-\varphi_{f}\left[\alpha(1-\alpha)\left(1+a_{f}\right)+\alpha^{2}\right]}{\tilde{\gamma}_{f}(\chi-1) \varphi_{f}\left(1+\tau_{f}\right)} .
$$

From (A.28), a constant $\theta$ implies

$$
\hat{P}_{Y}^{h}-\hat{P}_{Y}^{f}=\hat{Y}_{f}-\hat{Y}_{h}
$$

where we can substitute (20) and (A.25) to obtain (21). Also note that, from (A.29), a constant $\theta$ also implies that $E_{f}$ grows at the same rate as $P_{Y}^{f} Y_{f}$, which coincides with the growth rate of $E_{h}$ and $P_{Y}^{h} Y_{h}$ by (A.37) and (A.25). We thus have

$$
\hat{E}_{h}=\hat{E}_{f}=r_{i}-\rho \quad \text { with } \quad r_{h}=r_{f}
$$

Derivation of (22). Given $P_{R} R_{h}=\tilde{\gamma}_{h} P_{Y}^{h} Y_{h}$, the Hotelling rule (9) and result (A.25) imply that $P_{R} R_{h}$ grows at the rate $r_{h}-\rho$, so that $\hat{R}_{h}=-\rho$. A constant $\theta$ then implies $\hat{R}_{f}=-\rho$, which proves $(22)$. 
Derivation of (23). From (A.34), substitute $\bar{\sigma}_{f}^{c}=\chi \tilde{\gamma}_{f} \bar{\theta}$ in (A.30) to obtain $\bar{\sigma}_{f}^{d}=$ $1-\frac{\alpha^{2}}{1+b_{f}}-(\chi-1) \tilde{\gamma}_{f} \bar{\theta}$, and eliminate $(\chi-1) \tilde{\gamma}_{f} \bar{\theta}$ by (A.36) to obtain

$$
\bar{\sigma}_{f}^{d}=\frac{\varphi_{f} \alpha(1-\alpha)\left(1+a_{f}\right)-\rho\left(1+b_{f}\right)}{\varphi_{f}\left(1+b_{f}\right)} .
$$

From (7), both countries exhibit $\hat{M}_{i}=\varphi_{i} \bar{\sigma}_{i}^{d}$, and results (A.39) and (A.23) imply (23).

Derivation of (24). Defining $I_{i} \equiv \bar{\sigma}_{i}^{x}+\bar{\sigma}_{i}^{d}$ and substituting $\bar{\sigma}_{i}^{x}$ by (A.19) and $\bar{\sigma}_{i}^{d}$ by (A.23)-(A.39), we obtain (24).

Derivation of (25)-(26). Substituting the definition $E_{f}^{c}=\bar{\sigma}_{f}^{c} P_{Y}^{f} Y_{f}$ in (A.27), we have

$$
\frac{P_{Y}^{h} Y_{h}}{P_{Y}^{f} Y_{f}}=\frac{\epsilon \bar{\sigma}_{f}^{c}}{\tilde{\gamma}_{h}+(1-\epsilon) \bar{\sigma}_{h}^{c}} .
$$

Substituting $\bar{\sigma}_{f}^{c}=1+\tilde{\gamma}_{f} \bar{\theta}-\bar{\sigma}_{f}^{x}-\bar{\sigma}_{f}^{d}$ from (A.30), $\bar{\sigma}_{h}^{c}=1-\tilde{\gamma}_{h}-\bar{\sigma}_{h}^{x}-\bar{\sigma}_{h}^{d}$ from (A.21), and $\frac{P_{Y}^{h} Y_{h}}{P_{Y}^{f} Y_{f}}=\frac{\tilde{\gamma}_{f}}{\tilde{\gamma}_{h}} \bar{\theta}$ from (A.28), equation (A.40) yields $\frac{\tilde{\gamma}_{f}}{\tilde{\gamma}_{h}} \bar{\theta}=\frac{\epsilon\left(1-\bar{\sigma}_{f}^{x}-\bar{\sigma}_{f}^{d}\right)+\epsilon \tilde{\gamma}_{f} \bar{\theta}}{(1-\epsilon)\left(1-\bar{\sigma}_{h}^{x}-\bar{\sigma}_{h}^{d}\right)+\epsilon \tilde{\gamma}_{h}}$, which can be solved for $\bar{\theta}$ to get

$$
\bar{\theta}=\frac{\tilde{\gamma}_{h}}{\tilde{\gamma}_{f}} \cdot \frac{\epsilon\left(1-\bar{\sigma}_{f}^{x}-\bar{\sigma}_{f}^{d}\right)}{(1-\epsilon)\left(1-\bar{\sigma}_{h}^{x}-\bar{\sigma}_{h}^{d}\right)} .
$$

Substituting $I_{i} \equiv \bar{\sigma}_{i}^{x}+\bar{\sigma}_{i}^{d}$ in (A.41) and recalling that $\frac{\tilde{\gamma}_{h}}{\tilde{\gamma}_{f}}=\frac{1+\tau_{f}}{1+\tau_{h}}$, we get (26). Substituting (26) in (A.28), we obtain (25).

Closed-form solutions. For future reference, the closed-form solutions for output levels and prices are (see proofs in the Supplementary Material)

$$
\begin{gathered}
Y_{h}(t)=\frac{\left(\alpha^{2} / \varsigma\right)^{\frac{\alpha}{1-\alpha}}}{1+b_{h}} \cdot M_{h}(0)\left(v_{h}(0) L_{h}\right)^{\frac{\beta}{1-\alpha}}\left[\rho Q_{0} \bar{\theta} /(1+\bar{\theta})\right]^{\frac{\gamma}{1-\alpha}} \cdot e^{\left(\Omega_{h}-\rho\right) t}, \\
Y_{f}(t)=\frac{\left(\alpha^{2} / \varsigma\right)^{\frac{\alpha}{1-\alpha}}}{1+b_{f}} \cdot M_{f}(0)\left(v_{f}(0) L_{f}\right)^{\frac{\beta}{1-\alpha}}\left[\rho Q_{0} /(1+\bar{\theta})\right]^{\frac{\gamma}{1-\alpha}} \cdot e^{\left(\Omega_{f}-\rho\right) t}, \\
Y_{h}(t) / Y_{f}(t)=\bar{\theta}^{\frac{\gamma}{1-\alpha}} \cdot \psi_{0} \cdot e^{\left(\Omega_{h}-\Omega_{f}\right) t}, \\
P_{Y}^{h}(t) / P_{Y}^{f}(t)=\frac{\epsilon}{1-\epsilon} \cdot \frac{1-I_{f}}{1-I_{h}} \cdot \psi_{0}^{-1} \cdot \bar{\theta}^{-\frac{\gamma}{1-\alpha}} \cdot e^{-\left(\Omega_{h}-\Omega_{f}\right) t},
\end{gathered}
$$

where we have defined $\psi_{0} \equiv\left[\frac{M_{h}(0)}{M_{f}(0)}\left(\frac{1+b_{f}}{1+b_{h}}\right)\left(\frac{v_{h}(0) L_{h}}{v_{f}(0) L_{f}}\right)^{\frac{\beta}{1-\alpha}}\right]$.

Conditional efficiency: proof of result (28). See "Appendix B. Supplementary Material". 
Derivation of (31). Expression (31) directly follows from (17)-(18).

Derivation of (32)-(33). Defining the constant $\bar{\epsilon}_{i} \equiv\left(\epsilon / L_{i}\right)\left(\frac{1-\epsilon}{\epsilon}\right)^{1-\epsilon}$ and recalling that $E_{i}^{c}=\bar{\sigma}_{i}^{c} P_{Y}^{i} Y_{i}$ by (A.18), present-value utility (14) reads

$$
U_{i}=\int_{0}^{\infty} e^{-\rho t} \cdot \ln \left[\bar{\epsilon}_{i} \frac{\bar{\sigma}_{i}^{c} P_{Y}^{i} Y_{i}}{\left(P_{Y}^{h}\right)^{\epsilon}\left(P_{Y}^{f}\right)^{1-\epsilon}}\right] d t .
$$

Plugging the respective country indices, we obtain

$U_{h}=\int_{0}^{\infty} e^{-\rho t} \cdot \ln \left[\bar{\epsilon}_{h}\left(P_{Y}^{h} / P_{Y}^{f}\right)^{1-\epsilon} \bar{\sigma}_{h}^{c} Y_{h}\right] d t$ and $U_{f}=\int_{0}^{\infty} e^{-\rho t} \cdot \ln \left[\bar{\epsilon}_{f}\left(P_{Y}^{f} / P_{Y}^{h}\right)^{\epsilon} \bar{\sigma}_{f}^{c} Y_{f}\right] d t$.

Substituting $P_{Y}^{h}(t) / P_{Y}^{f}(t)=\left[P_{Y}^{h}(0) / P_{Y}^{f}(0)\right] e^{\left(\Omega_{f}-\Omega_{h}\right) t}$ from $(20)$, and $Y_{i}(t)=Y_{i}(0) e^{\left(\Omega_{i}-\rho\right) t}$ from (21), and collecting the terms to isolate the initial values, we can define

$$
\begin{aligned}
& \varkappa_{h} \equiv \int_{0}^{\infty} e^{-\rho t} \cdot \ln \left[e^{\left[\Omega_{h}-\rho+(1-\epsilon)\left(\Omega_{f}-\Omega_{h}\right)\right] t}\right] d t+\frac{1}{\rho} \ln \bar{\epsilon}_{h}, \\
& \varkappa_{f} \equiv \int_{0}^{\infty} e^{-\rho t} \cdot \ln \left[e^{\left[\Omega_{f}-\rho+\epsilon\left(\Omega_{h}-\Omega_{f}\right)\right] t}\right] d t+\frac{1}{\rho} \ln \bar{\epsilon}_{f},
\end{aligned}
$$

and rewrite $U_{h}$ and $U_{f}$ as in (32)-(33).

Consumption propensities: derivation of (34)-(35). From (A.21), Home's consumption propensity is defined as $\bar{\sigma}_{h}^{c}=1-\tilde{\gamma}_{h}-\left(\bar{\sigma}_{h}^{d}+\bar{\sigma}_{h}^{x}\right)$, where we can substitute $I_{h}=\bar{\sigma}_{h}^{d}+\bar{\sigma}_{h}^{x}$ from (A.22), as well as the definition of tax-adjusted resource elasticity $\tilde{\gamma}_{i} \equiv \gamma\left(1+\tau_{i}\right)^{-1}$, to obtain (34). Considering Foreign, result (A.34) establishes $\bar{\sigma}_{f}^{c}=\chi \tilde{\gamma}_{f} \theta$, where we can substitute the definition of $\chi$ given in (A.33) to obtain

$$
\bar{\sigma}_{f}^{c}=\chi \tilde{\gamma}_{f} \theta=\left(\frac{\tilde{\gamma}_{f}}{\epsilon}+\frac{1-\epsilon}{\epsilon} \cdot \frac{\tilde{\gamma}_{f}}{\tilde{\gamma}_{h}} \bar{\sigma}_{h}^{c}\right) \cdot \theta
$$

and then substitute $\theta$ with the equilibrium level $\bar{\theta}$ given in (26), obtaining

$$
\bar{\sigma}_{f}^{c}=\frac{1}{1-\epsilon} \frac{\gamma}{1+\tau_{h}} \frac{1-I_{f}}{1-I_{h}}+\bar{\sigma}_{h}^{c} \cdot \frac{1-I_{f}}{1-I_{h}} .
$$

Substituting $\bar{\sigma}_{h}^{c}$ by means of (34), equation (A.47) yields

$$
\bar{\sigma}_{f}^{c}=\frac{1}{1-\epsilon} \frac{\gamma}{1+\tau_{h}} \frac{1-I_{f}}{1-I_{h}}+\left(1-I_{f}\right)-\frac{\gamma}{1+\tau_{h}} \cdot \frac{1-I_{f}}{1-I_{h}},
$$

which reduces to expression (35). 
Derivation of results (36)-(37). From (A.42), (A.43) and (A.45), we have

$$
\begin{aligned}
\frac{\mathrm{d} \ln Y_{h}(0)}{\mathrm{d} \tau_{h}} & =\frac{\gamma}{1-\alpha} \cdot \frac{\mathrm{d} \ln [\bar{\theta} /(1+\bar{\theta})]}{\mathrm{d} \tau_{h}}=\frac{\gamma}{1-\alpha} \cdot \frac{1}{1+\bar{\theta}} \cdot \frac{\mathrm{d} \ln \bar{\theta}}{\mathrm{d} \tau_{h}}<0, \\
\frac{\mathrm{d} \ln Y_{f}(0)}{\mathrm{d} \tau_{f}} & =\frac{\gamma}{1-\alpha} \cdot \frac{\mathrm{d} \ln [1 /(1+\bar{\theta})]}{\mathrm{d} \tau_{f}}=-\frac{\gamma}{1-\alpha} \cdot \frac{\bar{\theta}}{1+\bar{\theta}} \cdot \frac{\mathrm{d} \ln \bar{\theta}}{\mathrm{d} \tau_{f}}<0, \\
\frac{\mathrm{d} \ln p_{0}}{\mathrm{~d} \tau_{h}} & =-\frac{\gamma}{1-\alpha} \cdot \frac{\mathrm{d} \ln \bar{\theta}}{\mathrm{d} \tau_{h}}>0, \\
\frac{\mathrm{d} \ln p_{0}}{\mathrm{~d} \tau_{f}} & =-\frac{\gamma}{1-\alpha} \cdot \frac{\mathrm{d} \ln \bar{\theta}}{\mathrm{d} \tau_{f}}<0,
\end{aligned}
$$

where $p_{0} \equiv P_{Y}^{h}(0) / P_{Y}^{f}(0)$. The signs in (A.48)-(A.51) come from $d \bar{\theta} / d \tau_{h}<0$ and $d \bar{\theta} / d \tau_{f}>0$ as implied by (26). These results imply the signs of terms-of-trade effects and physical-output effects reported in (36)-(37). Considering the consumption-share effect in Home, expression (34) implies

$$
\frac{\mathrm{d} \ln \bar{\sigma}_{h}^{c}}{\mathrm{~d} \tau_{h}}=\frac{1}{1+\tau_{h}} \cdot \frac{\tilde{\gamma}_{h}}{\bar{\sigma}_{h}^{c}}=\frac{1}{1+\tau_{h}} \cdot \frac{\tilde{\gamma}_{h}}{1-\tilde{\gamma}_{h}-I_{h}}>0
$$

where the last term comes from substituting $I_{h}=\bar{\sigma}_{h}^{x}+\bar{\sigma}_{h}^{d}$ in (A.22). In Foreign, equation (35) implies

$$
\frac{\mathrm{d} \ln \bar{\sigma}_{f}^{c}}{\mathrm{~d} \tau_{f}}=0 .
$$

Proof of Proposition 3 (Foreign). Substituting (A.49) and (A.51) in (37), and using $d \ln \bar{\theta} / d \tau_{f}=\left(1+\tau_{f}\right)$ from (26), we have

$$
\rho \cdot \frac{d U_{f}}{d \tau_{f}}=\frac{\gamma\left(1+\tau_{f}\right)}{1-\alpha} \cdot\left[\epsilon-\frac{\bar{\theta}}{1+\bar{\theta}}\right]
$$

the sign of which is determined by the term in square brackets. As $\bar{\theta}$ is monotonously increasing in $\tau_{f}$ by (26), the condition $\mathrm{d} U_{f} / \mathrm{d} \tau_{f}=0$ is univoquely associated to a Foreign $\operatorname{tax} \tau_{f}^{\max }$ associated to a relative resource use $\bar{\theta}_{f}^{\max }=\epsilon /(1-\epsilon)$. The condition $\mathrm{d} U_{f} / \mathrm{d} \tau_{f}=$ 0 identifies a maximum of $U_{f}$ because (A.54) implies $\mathrm{d} U_{f} / \mathrm{d} \tau_{f}>0$ when $\bar{\theta}<\epsilon /(1-\epsilon)$ and $\mathrm{d} U_{f} / \mathrm{d} \tau_{f}<0$ when $\bar{\theta}>\epsilon /(1-\epsilon)$.

Proof of Proposition 3 (Home). Substituting (A.48), (A.50) and (A.53) in (36),

$$
\rho \cdot \frac{\mathrm{d} U_{h}}{\mathrm{~d} \tau_{h}}=-\frac{\gamma(1-\epsilon)}{1-\alpha} \cdot \frac{\mathrm{d} \ln \bar{\theta}}{\mathrm{d} \tau_{h}}+\frac{\gamma}{1-\alpha} \cdot \frac{1}{1+\bar{\theta}} \cdot \frac{\mathrm{d} \ln \bar{\theta}}{\mathrm{d} \tau_{h}}+\frac{1}{1+\tau_{h}} \cdot \frac{\tilde{\gamma}_{h}}{1-\tilde{\gamma}_{h}-I_{h}} .
$$


From (26), we have $\operatorname{d} \ln \bar{\theta} / \mathrm{d} \tau_{h}=-\left(1+\tau_{h}\right)^{-1}$ and the above expression reduces to

$$
\rho \cdot \frac{\mathrm{d} U_{h}}{\mathrm{~d} \tau_{h}}=\frac{\gamma}{1+\tau_{h}} \cdot\left\{\frac{1}{\left(1+\tau_{h}\right)\left(1-\tilde{\gamma}_{h}-I_{h}\right)}-\frac{1}{1-\alpha} \cdot\left[\frac{1}{1+\bar{\theta}}-(1-\epsilon)\right]\right\},
$$

the sign of which is determined by the term in curly brackets: defining $\Upsilon^{a}\left(\tau_{h}\right) \equiv 1 /$ $\left[\left(1+\tau_{h}\right)\left(1-\tilde{\gamma}_{h}-I_{h}\right)\right]$ and $\Upsilon^{b}\left(\tau_{h}\right) \equiv \frac{1}{1-\alpha} \cdot\left[\frac{1}{1+\theta}-(1-\epsilon)\right]$, we have

$$
\rho \cdot \frac{\mathrm{d} U_{h}}{\mathrm{~d} \tau_{h}}=\frac{\gamma}{1+\tau_{h}} \cdot\left[\Upsilon^{a}\left(\tau_{h}\right)-\Upsilon^{b}\left(\tau_{h}\right)\right] .
$$

where $\Upsilon^{a}\left(\tau_{h}\right)$ is strictly decreasing in $\tau_{h}$ and satisfies $\lim _{\tau_{h} \rightarrow \infty} \Upsilon^{a}\left(\tau_{h}\right)=0$, while $\Upsilon^{b}\left(\tau_{h}\right)$ is strictly increasing in $\tau_{h}$ and satisfies $\lim _{\tau_{h} \rightarrow \infty} \Upsilon^{b}\left(\tau_{h}\right)=\frac{\epsilon}{1-\alpha}>0$. Therefore, $U_{h}$ is a hump-shaped function of $\tau_{h}$, with a unique maximum in $\tau_{h}=\tau_{h}^{\max }$ associated to $\Upsilon^{a}\left(\tau_{h}^{\max }\right)=\Upsilon^{b}\left(\tau_{h}^{\max }\right) \rightarrow \mathrm{d} U_{h} / \mathrm{d} \tau_{h}=0$. Consider any level $\breve{\tau}_{R}^{h}$ of the Home tax such that relative resource use is $\bar{\theta}=\epsilon /(1-\epsilon)$ : from (A.55) and (A.56), we have $\Upsilon^{a}\left(\breve{\tau}_{R}^{h}\right)>$ $\Upsilon^{b}\left(\breve{\tau}_{R}^{h}\right)=0$ and $\mathrm{d} U_{h} / \mathrm{d} \tau_{h}>0$. Hence, the condition $\mathrm{d} U_{h} / \mathrm{d} \tau_{h}=0$ is associated to a resource tax $\tau_{h}^{\max }>\breve{\tau}_{R}^{h}$ and a level of relative resource use $\theta_{h}^{\max }<\epsilon /(1-\epsilon)$. For future reference, we can express $\theta_{h}^{\max }$ as follows. From (A.55), the tax rate $\tau_{h}^{\max }$ is associated to the condition

$$
\frac{1}{\left(1+\tau_{h}^{\max }\right)\left(1-\tilde{\gamma}_{h}-I_{h}\right)}=\frac{1}{1-\alpha} \cdot\left[\frac{1}{1+\theta_{h}^{\max }}-(1-\epsilon)\right]
$$

which, using the definition $\tilde{\gamma}_{h} \equiv \gamma\left(1+\tau_{h}\right)^{-1}$, may be equivalently written as

$$
\frac{1}{1+\theta_{h}^{\max }}=1-\epsilon+\frac{1-\alpha}{\left(1+\tau_{h}^{\max }\right)\left(1-I_{h}\right)-\gamma} .
$$

The last term in (A.57) can be denoted as

$$
\Lambda\left(\tau_{h}^{\max }\right) \equiv \frac{1-\alpha}{\left(1+\tau_{h}^{\max }\right)\left(1-I_{h}\right)-\gamma}>0
$$

which is strictly positive because this is necessary to have a positive propensity to consume $\bar{\sigma}_{f}^{c}>0$ in Home (see (34) and the associated feasibility restriction (40) in the main text). Using definition (A.58), we can solve (A.57) for $\theta_{h}^{\max }$, obtaining

$$
\theta_{h}^{\max }=\frac{\epsilon-\Lambda\left(\tau_{h}^{\max }\right)}{1-\epsilon+\Lambda\left(\tau_{h}^{\max }\right)},
$$


which is indeed strictly less than $\epsilon /(1-\epsilon)$, as claimed before.

Proof of Proposition 4. Assuming $\bar{\theta}=\epsilon /(1-\epsilon)$, we have $\mathrm{d} U_{f} / \mathrm{d} \tau_{f}=0$ from (A.54) and $\mathrm{d} U_{h} / \mathrm{d} \tau_{h}>0$ from (A.56).

Proof of Proposition 5. In a laissez-faire equilibrium, $\bar{\theta}$ is given by (27). If $\varphi_{h}=\varphi_{f}$ we have $\bar{\theta}=\epsilon /(1-\epsilon)$, in which case $\mathrm{d} U_{f} / \mathrm{d} \tau_{f}=0$ and $\mathrm{d} U_{h} / \mathrm{d} \tau_{h}>0$ by Proposition 4 . If $\varphi_{h}>\varphi_{f}$, we have $\bar{\theta}>\epsilon /(1-\epsilon)$, implying $\mathrm{d} U_{f} / \mathrm{d} \tau_{f}<0$ from (A.54) and $\mathrm{d} U_{h} / \mathrm{d} \tau_{h}>0$ from (A.55). If $\varphi_{h}<\varphi_{f}$, we have $\bar{\theta}<\epsilon /(1-\epsilon)$, which implies $\mathrm{d} U_{f} / \mathrm{d} \tau_{f}>0$ from (A.54) whereas, from (A.56), the sign of $\mathrm{d} U_{h} / \mathrm{d} \tau_{h}$ is generally ambiguous.

Derivation of (41). From Proposition 3, Foreign government can maximize $U_{f}$ for given $\tau_{h}$ by implementing a tax rate $\tau_{f}^{\max }$ that implies $\bar{\theta}=\frac{\epsilon}{1-\epsilon}$. From this best-response condition, substitute the definition of $\bar{\theta}$ given in (26), and set $\tau_{f}=\tau_{f}^{\max }$, to obtain

$$
\tau_{f}^{\max }=\frac{1-I_{h}}{1-I_{f}} \cdot\left(1+\tau_{h}\right)-1
$$

Expression (A.60) defines $\tau_{f}^{\max }$ as a best response to any $\tau_{h}$ so that we can substitute $\tau_{f}^{\max }=\tau_{f}^{B}$, and define the right hand side as $B_{f}\left(\tau_{f}\right)$, obtaining expression (41) in the text.

Derivation of (42). In Home, the welfare-maximizing tax rate $\tau_{h}^{\max }$ is associated to the equilibrium level of relative resource use (A.59). Substituting $\theta_{h}^{\max }$ with the equilibrium level $\bar{\theta}$ given in (26), expression (A.59) yields

$$
\frac{1+\tau_{f}}{1+\tau_{h}^{\max }} \cdot \frac{\epsilon}{1-\epsilon} \cdot \frac{1-I_{f}}{1-I_{h}}=\frac{\epsilon-\Lambda\left(\tau_{h}^{\max }\right)}{1-\epsilon+\Lambda\left(\tau_{h}^{\max }\right)},
$$

where $\Lambda\left(\tau_{h}^{\max }\right)$ is defined in (A.58). Expression (A.61) implicitly defines $\tau_{h}^{\max }$ as a best response $B_{h}\left(\tau_{f}\right)$ to any $\tau_{f}$. Substituting $\tau_{h}^{\max }=\tau_{h}^{B}$ in the above expression, and solving for $\tau_{f}$, we obtain expression (42) in the text, where the right hand side is the inverse bestresponse function $B_{h}^{-1}\left(\tau_{h}^{B}\right)$. Being $\Lambda\left(\tau_{h}^{B}\right)>0$, the term in curly brackets in (42) is strictly below unity for any feasible finite value of $\tau_{h}^{B}$ and converges to unity asymptotically as $\tau_{h} \rightarrow+\infty$ 
Derivation of (45)-(46). From (32)-(33), welfare levels may be written as

$$
\begin{aligned}
& U_{h}=\varkappa_{h}+\frac{1}{\rho} \ln \left\{\left[p_{0}^{1-\epsilon} Y_{h}(0)\right] \cdot \bar{\sigma}_{h}^{c}\right\}, \\
& U_{f}=\varkappa_{f}+\frac{1}{\rho} \ln \left\{\left[p_{0}^{1-\epsilon} \frac{Y_{f}(0)}{p_{0}}\right] \cdot \bar{\sigma}_{f}^{c}\right\},
\end{aligned}
$$

where the terms in square brackets have an identical core term that is a function of $\bar{\theta}$. To see this, use the closed-form solutions (A.42), (A.43) and (A.45) evaluated at time $t=0$ to obtain

$$
\begin{aligned}
Y_{h}(0) & =\mathcal{F}_{H} \cdot\left(\frac{\bar{\theta}}{1+\bar{\theta}}\right)^{\frac{\gamma}{1-\alpha}} \\
\frac{Y_{f}(0)}{p_{0}} & =\mathcal{F}_{F} \cdot\left(\frac{\bar{\theta}}{1+\bar{\theta}}\right)^{\frac{\gamma}{1-\alpha}} \\
p_{0}^{1-\epsilon} & =\mathcal{F}_{p} \cdot \bar{\theta}^{-\frac{\gamma}{1-\alpha}(1-\epsilon)}
\end{aligned}
$$

where $\mathcal{F}_{H}, \mathcal{F}_{F}, \mathcal{F}_{p}$ are constants that do not depend on resource taxes. Plugging these expressions into (A.62) and (A.63), and defining the country-specific constants $\tilde{\varkappa}_{i} \equiv$ $\varkappa_{i}+\frac{1}{\rho} \ln \mathcal{F}_{i} \mathcal{F}_{p}$ for each country $i=h, f$ we get

$$
U_{i}=\tilde{\varkappa}_{i}+\frac{1}{\rho} \ln \left\{\left(\frac{\bar{\theta}^{\epsilon}}{1+\bar{\theta}}\right)^{\frac{\gamma}{1-\alpha}} \cdot \bar{\sigma}_{i}^{c}\right\}
$$

in each country $i=h, f$. From (A.64), we can define the function $\Gamma(\bar{\theta})$ as in (47), and substitute the respective consumption propensities $\bar{\sigma}_{i}^{c}$ from (34)-(35) to obtain expressions (45) and (46) in the text.

Derivation of (48). Substituting $\tau_{h}^{\max }$ with the best response function $\tau_{h}^{\max }\left(\tau_{f}\right)=$ $B_{h}\left(\tau_{f}\right)$, the equilibrium level of relative resource use $\bar{\theta}=\theta_{h}^{\max }$ calculated in expression (A.59) directly yields $\theta^{S 2}$ in the form of expression (48) in the text. From (42), the functions $B_{h}(\cdot)$ and $\Lambda(\cdot)$ respectively exhibit $B_{h}^{\prime}(\cdot)>0$ and $\Lambda(\cdot)^{\prime}<0$. This implies $\mathrm{d} \theta^{S 2}\left(\tau_{f}\right) / \mathrm{d} \tau_{f}>0$ because an increase in $\tau_{f}$ increases $B_{h}\left(\tau_{f}\right)$, which then reduces $\Lambda\left(B_{h}\left(\tau_{f}\right)\right)$, which then increases $\theta^{S 2}\left(\tau_{f}\right)$.

Derivation of (50), (51) and Proposition 6. By definition (47), the function $\Gamma(\bar{\theta})$ is hump-shaped in $\bar{\theta}$ and exhibits a global maximum characterized by $\Gamma^{\prime}(\bar{\theta})=0$, 
which is associated to the efficient level of relative resource use: ${ }^{20}$

$$
\arg \max _{\{\bar{\theta}\}} \Gamma(\bar{\theta})=\frac{\epsilon}{1-\epsilon}
$$

In expression (49), we have $\Gamma\left(\theta^{S 2}\left(\tau_{f}\right)\right)$ where $\theta^{S 2}\left(\tau_{f}\right)$ is defined in (48) and is always strictly lower than the efficient level $\frac{\epsilon}{1-\epsilon}$. Therefore, any situation in which $\bar{\theta}=\theta^{S 2}\left(\tau_{f}\right)$ implies that we are to the left of the maximum of $\Gamma(\bar{\theta})$ and, hence,

$$
\frac{\partial \Gamma\left(\theta^{S 2}\right)}{\partial \theta^{S 2}}>0, \quad \frac{\partial^{2} \Gamma\left(\theta^{S 2}\right)}{\partial\left(\theta^{S 2}\right)^{2}}<0, \quad \lim _{\theta^{S 2} \rightarrow \frac{\epsilon}{1-\epsilon}} \frac{\partial \Gamma\left(\theta^{S 2}\right)}{\partial \theta^{S 2}}=0 .
$$

Combining results (A.66) with those established in (48) we have

$$
\frac{\mathrm{d} \Gamma\left(\theta^{S 2}\left(\tau_{f}\right)\right)}{\mathrm{d} \tau_{f}}>0, \quad \lim _{\tau_{f} \rightarrow \infty} \frac{\mathrm{d} \Gamma\left(\theta^{S 2}\left(\tau_{f}\right)\right)}{\mathrm{d} \tau_{f}}=0 .
$$

Now consider the welfare function (49), which depends on $\tau_{f}$ via both $\Gamma\left(\theta^{S 2}\left(\tau_{f}\right)\right)$ and the last term, which represents the propensity to consume

$$
\frac{1}{\rho} \ln \bar{\sigma}_{f}^{c}=\frac{1}{\rho} \ln \left[1-I_{f}+\frac{\gamma}{1+B_{h}\left(\tau_{f}\right)} \cdot \frac{\epsilon}{1-\epsilon} \cdot \frac{1-I_{f}}{1-I_{h}}\right]
$$

and displays the following properties ${ }^{21}$

$$
\frac{\mathrm{d} \bar{\sigma}_{f}^{c}}{\mathrm{~d} \tau_{f}}=\frac{\partial \bar{\sigma}_{f}^{c}}{\partial B_{h}} \cdot \frac{\partial B_{h}\left(\tau_{f}\right)}{\partial \tau_{f}}<0, \quad \lim _{\tau_{f} \rightarrow \infty} \frac{\mathrm{d} \bar{\sigma}_{f}^{c}}{\mathrm{~d} \tau_{f}}=0 .
$$

The above properties imply the total derivative (51).

\footnotetext{
${ }^{20}$ Setting the derivative of function $\Gamma(\bar{\theta})$ equal to zero yields the necessary condition $\epsilon \bar{\theta}^{\epsilon-1}(1+\bar{\theta})=\bar{\theta}^{\epsilon}$ which reduces to (A.65). Note, in passing, that result (A.65) represents the basis for an alternative proof of Proposition 3 since it implies that $\tau_{f}^{\max }$ is always associated to efficient relative resource use.

${ }^{21}$ The sign of $\partial B_{h}\left(\tau_{f}\right) / \partial \tau_{f}$ is strictly positive from expression $(42)$, which implies $B_{h}^{\prime}(\cdot)>0$.
} 


\section{Figures}

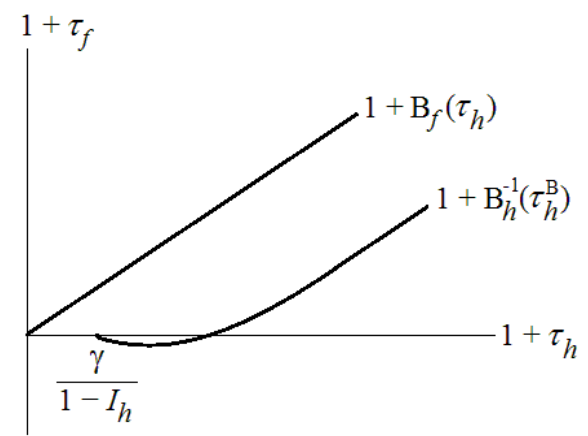

Graph (a)

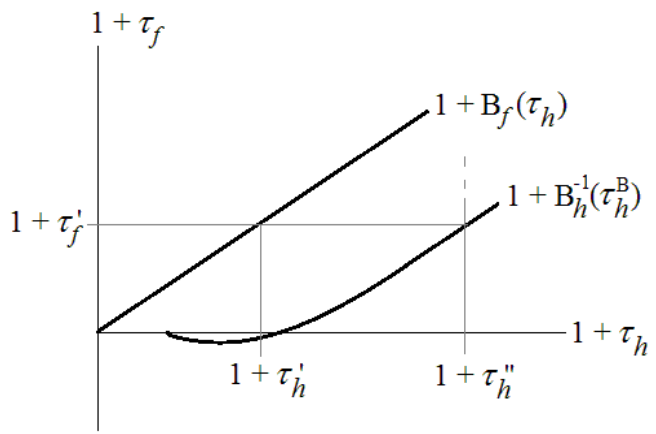

Graph (b)

Figure 1: Best response functions for governments in a one-shot game with simultaneous moves. Graph (a): non-existence of a Nash equilibrium in pure strategies. Graph (b): interpretation in terms of everlasting tax war. 

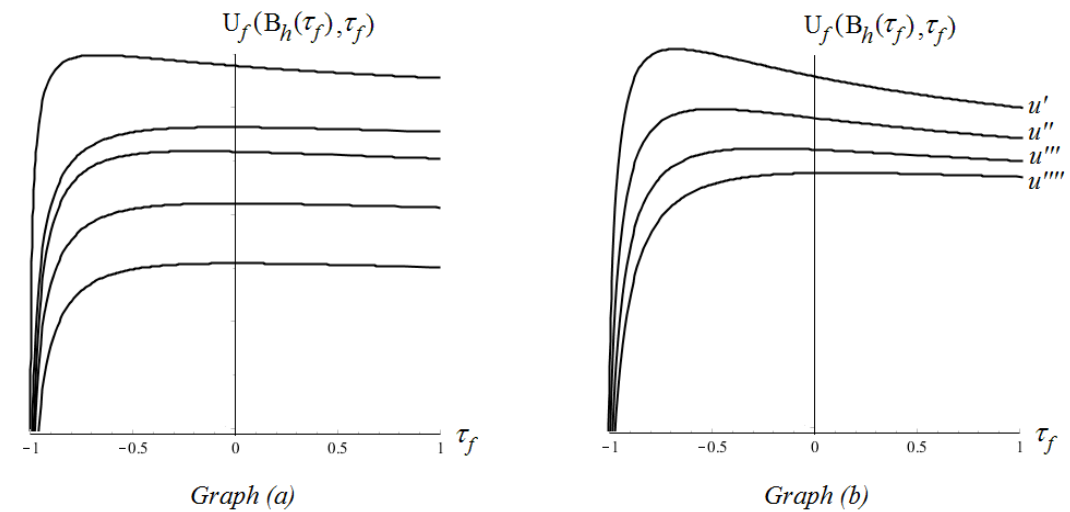

Figure 2: Stackelberg equilibria when Foreign moves first. Graph (a): existence of equilibria for different combinations of parameter values. Graph (b): Stackelberg equilibria calculated for different values of $\epsilon$ display $\tau_{f}^{S 1}<0$ for $\epsilon=0.55,0.60,0.65$. 